\title{
Simulation and Analysis of 48v Mild Hybrid, CVT, and Upcoming Powertrain Control Strategies for Increasing Light Vehicle Fuel Efficiency
}

\author{
Shantanu Pardhi \\ Powertrain Engineer \\ Paris, France
}

\begin{abstract}
Due to the ever-increasing need for reducing global warming the automotive sector today is going through a big change. New emission norms are being put to penalize companies whose cars emit $\mathrm{CO} 2$ greenhouse gas above a low set limit $(95 \mathrm{~g} / \mathrm{km}$ in Europe from 2021) leading to a push towards hybridization and electrification which release less or no tailpipe emissions. However, such a drastic change in propulsion techniques can lead to various issues such as environmental hazards in production and vehicle afterlife, increased product cost, and increased burden on electric grids to name a few. The trend thus is to follow a smooth long term transition by engineering and implementing cost-effective techniques that help meet the current, upcoming emission regulations, reduce fuel consumption and also promote a move towards feasible future powertrain electrification. This paper presents modeling, simulation analysis, and comparison of the current state of the art of powertrain control strategies such as optimal gear shift control, start-stop, coasting and continuously variable transmission, mild hybridization technologies being developed, or used to meet the upcoming objectives.
\end{abstract}

Keywords-Powertrain efficiency; CO2 emissions; 48-volt mild hybrid; continuously variable transmission CVT; start-stop; coasting; optimal gear shift; fuel economy; modeling; simulation

\section{IINTRODUCTION}

With a global need for decreasing automotive emissions [12] and increasing fuel efficiency, automakers are implementing innovative powertrain technologies and control strategies to meet the upcoming $\mathrm{CO} 2$ emission targets. With the possibility of using ingenious technologies and their various combined architectures to meet the efficiency objectives, it becomes more and more important for automotive engineers to understand, choose and develop powertrains that are optimally suited for specific applications at minimal costs. The applications could be defined by the vehicle characteristics, required operation such as the driving scenario, load capacity, and the desired performance, drivability, and emission targets. The current work is a study of mild hybridization and continuously variable transmission application along with upcoming powertrain control strategies such as start-stop, coasting, and optimal gear shifting in increasing vehicle fuel efficiency. Starting with modeling and simulation of a conventional powertrain as the baseline, the application of these techniques was carried out to facilitate analysis and comparison of their advantages. For base case study the application of light vehicle was considered as they tend to be pre-optimized for fuel efficiency with a downsized combustion engine and pose a significant challenge to the effectiveness of these techniques. Their success in such a case will assure even better outcomes for applications that are heavier or more performance-oriented. Due to the availability of data the light vehicle considered for our study was a Smart Fortwo from 2001 driving on the WLTC cycle with 1 passenger. If the case study is an old vehicle the advantage of these techniques can be seen even more explicitly in making them current day regulations compliant. A suitable weight penalty was considered in the implementation of technologies such as mild hybridization (TABLE 5). First, the approximation for powertrain losses and the quasi-static numerical modeling approach considered is discussed. Then the results of the simulation for our selected conventional vehicle are shown to provide an idea about its performance and how its simulation matches closely to that of the actual vehicle for a general fixed gear shift strategy. The new powertrain techniques and their functioning are then discussed in brief followed by the results of their implementation on our base vehicle.

\section{II.POWERTRAIN MODELING}

To study the advantages of innovative technologies and upcoming control methods, the complete powertrain modeling approach was kept quasi-static in nature. This was done to avoid the need for unnecessary high-level controls, precise calibrations, complexity of developing models, and running simulations while still getting a fairly precise result that is close to the real system.

The models are run in a backward manner by calculating tractive forces from vehicle characteristics and driving cycle velocity needs, then torque and speed at wheels followed by torque and speed between the gearbox and combustion engine that the engine has to provide [1]. Effect of rotational, longitudinal inertia, and a close approximation of different losses in powertrain components $(T A B L E 1)$ is taken into account.

TABLE 1 POWERTRAIN LOSSES

\begin{tabular}{|l|l|}
\hline \multicolumn{2}{|c|}{ Engine } \\
\hline $\begin{array}{l}\text { Engine friction torque (at idle) } \\
(10 \% \text { of peak engine brake torque) }\end{array}$ & $8[\mathrm{Nm}]$ \\
\hline Combustion engine efficiency $\eta_{\text {eng_BTE }}$ & Map - based (Fig. 6$)$ \\
\hline
\end{tabular}




\begin{tabular}{|l|l|}
\hline \multicolumn{2}{|c|}{ Transmission } \\
\hline Gear train (each gear pair) efficiency & $98[\%]$ \\
\hline Clutch, tyre slip efficiency & $99[\%]$ \\
\hline Overall transmission efficiency $\eta_{\text {trns }}$ & $93[\%]$ \\
\hline CVT loss depending on gear ratio [11] & Map - based (Fig. 14) \\
\hline \multicolumn{2}{|c|}{ Hybrid system } \\
\hline Li-ion cell resistance $R$ for Ohmic loss & 0.02 [ohms] \\
\hline Battery architecture & 12 cells in series \\
\hline Electric motor efficiency $\eta_{m t r}[11]$ & Map - based (Fig. 25) \\
\hline Power electronics efficiency $\eta_{P E}$ & $96[\%]$ (per conversion) \\
\hline
\end{tabular}

Tractive force $F_{\text {tract }}$ is the overall force that the vehicle needs against aerodynamic drag $F_{\text {aero }}$, rolling resistance $F_{\text {roll }}$, longitudinal inertia of the vehicle $F_{\text {inert-l }}$, and road inclination $F_{\text {inclin }}$ to follow a certain velocity profile [2].

$$
\begin{aligned}
& F_{\text {tract }}=F_{\text {aero }}+F_{\text {roll }}+F_{\text {inert }-l}+F_{\text {inclin }} \\
& \begin{aligned}
F_{\text {tract }}=\frac{1}{2} \rho A C_{d} V^{2}+C_{r r} m g+m a \\
+m g \sin \theta
\end{aligned} \\
& T_{\text {tract }}=F_{\text {tract }} r_{w}
\end{aligned}
$$

Where, $\rho$ is air density, $A$ vehicle frontal area, $C_{d}$ aerodynamic drag coefficient, $V$ vehicle speed, $C_{r r}$ coefficient of rolling resistance, $m$ mass of vehicle, $a$ vehicle acceleration, $g$ acceleration due to gravity, $\theta$ road inclination angle, $r_{w}$ wheel radius and $T_{\text {tract }}$ is the tractive.

Tractive power $P_{\text {tract }}$,

$$
P_{\text {tract }}=F_{\text {tract }} \frac{d x}{d t}=\frac{2 \pi N_{w} T_{\text {tract }}}{60}
$$
$T_{w}$

Torque needed at the wheel for traction and wheel inertia

$$
T_{w}=T_{\text {tract }}+J_{w} \frac{d \omega_{w}}{d t}-T_{\text {brakes }}
$$

Power at the wheels $P_{w}$,

$$
P_{w}=\frac{2 \pi N_{w} T_{w}}{60}
$$

Transmission torque $T_{\text {trns }}$,

$$
T_{t r n s}=T_{w}+J_{t r n s} \frac{d \omega_{t r n s}}{d t}
$$

Engine torque $T_{\text {eng }}$ and speed $N_{\text {eng }}$,

$$
\begin{gathered}
T_{\text {eng }}=\left(\frac{T_{\text {trns }}}{G R * \eta_{\text {trns }}}+J_{\text {eng }} \frac{d \omega_{\text {eng }}}{d t}\right) \\
N_{\text {eng }}=N_{w} G R=N_{\text {trns }} G R
\end{gathered}
$$

Where, $J_{w}, J_{\text {trns }}, J_{\text {eng }}$ are the rotational inertia of the wheels, the complete transmission, the engine, and $\omega_{w}, N_{w}$, $\omega_{\text {trns }}, N_{\text {trns }}, \omega_{\text {eng }}, N_{\text {eng }}$ are the angular velocities of wheels, transmission, and combustion engine respectively.

Engine brake power $P_{\text {eng }}$ and fuel flow rate,

$$
\begin{gathered}
P_{\text {eng }}=\frac{2 \pi N_{\text {eng }} T_{\text {eng }}}{60} \\
\frac{d m_{f}}{d t}=\frac{P_{\text {eng }}}{\eta_{\text {eng_BTE }} L H V_{\text {fuel }}}
\end{gathered}
$$

Where, $L H V_{\text {fuel }}$ is the lower heating value of the fuel.

Vehicle fuel economy,

$$
\frac{m_{f_{-} t o t}}{x_{t o t}}
$$

Power given to the electric motor for traction $P_{\text {elec }}$,

$$
P_{\text {elec }}=\frac{P_{m t r}}{\eta_{m t r}}
$$

$P_{m t r}, T_{m t r}, N_{m t r}$ are electric motor power, torque and speed.

Power from the electric motor in regenerative braking or charging $P_{\text {elec }}$,

$$
P_{\text {elec }}=P_{m t r} \eta_{m t r}
$$

Electric power needed from battery for traction $P_{b a t}$,

$$
P_{b a t}=\frac{P_{e l e c}}{\eta_{P E}}
$$

Electric power from regenerative braking and charging to battery $P_{\text {bat }}$,

$$
P_{\text {bat }}=P_{\text {elec }} \eta_{P E}
$$

Power given by the battery considering ohmic losses,

$$
V_{o c} I_{b a t}=P_{b a t}+I_{b a t}^{2} R
$$


Power to battery in regenerative braking and charging,

$$
\begin{gathered}
V_{o c} I_{b a t}=P_{b a t}-I_{b a t}{ }^{2} R \\
S O C=\int_{0}^{t} I_{b a t} \cdot d t / Q_{\text {max }} ; V_{o c}=f(S O C)
\end{gathered}
$$

Where, $V_{o c}$ is battery open circuit voltage and $I_{b a t}$ the current, SOC state of charge, $Q_{\max }$ the maximum charge capacity of the battery.

\section{ANALYSIS}

To study the effects of start-stop, coasting strategy, CVT, and mild hybridization, first simulation for the standard powertrain was carried out followed by results analysis to get a general idea. The WLTC test cycle, selected vehicle, powertrain, and controls data for our case was loaded onto the model along with approximation of losses (TABLE 5 and $T A B L E$ 1) and the following results were seen for cycle simulation.

\section{A. Standard powertrain}

The backward powertrain model follows the WLTC driving cycle, which is the current norm for testing fuel consumption and emissions in Europe and in some other parts of the world.

With the combined effect of various tractive forces against vehicle movement discussed earlier, the total tractive torque profile needed at the wheels to follow the WLTC cycle velocity was calculated. The positive parts in Fig. 1 show the amount of torque to be given to the wheels by the powertrain $T_{\text {tract }}$. The negative parts show the torque to be taken from the wheels $T_{\text {brake }}$ (given in the opposite direction) using brakes or regenerative braking to charge the battery in a hybrid or electric system.

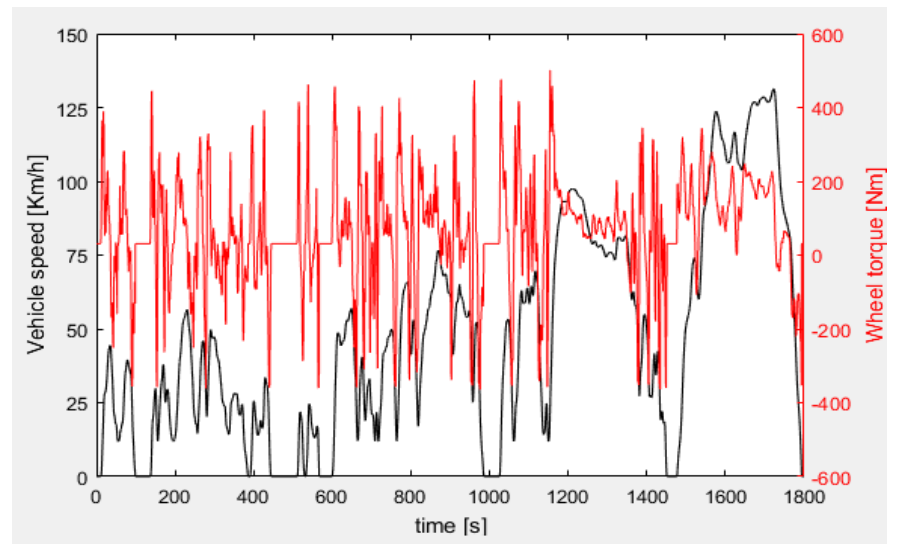

Fig. 1. Vehicle speed and wheel torque on WLTC cycle

To properly launch, accelerate and cover all operating ranges for tractive force and speed, and to make the vehicle able to achieve better fuel economy, a prime mover may need a gearbox with the possibility of using various gear ratio $G R$ selections depending on its operating conditions and the control strategy.
The gearbox control decides on the gear selection and shift depending on the instantaneous torque (load demand), speed while respecting the constraints of the combustion engine for maximum torque, maximum and minimum speed limit to meet the desired objective such as running the prime mover for maximizing performance, fuel efficiency or drivability. Depending on the objective the gearbox control can be developed and tuned by altering the operating region of the prime mover within its limits.

In our case, since the objective is to achieve better fuel economy with initially a conventional fixed gear shift strategy, the combustion engine is made to operate in a certain selected region with the overall high engine efficiency by putting fixed constraints in terms of engine speed and brake torque which when the engine surpasses a gear change occurs to bring it back into the desired operating area. The selected region should be able to make the engine run in its full power range while avoiding control issues such as gear hunting. In our case the fixed control comprised of lines defining lower speed limit (green downshift line), higher speed limit (blue upshift line) and maximum possible torque limit (red downshift line) that encircle the desired region of engine operation (Fig. 2).

Upshift - Operating point crosses upshift speed $N_{\text {upshift }}$

$$
N_{\text {eng }}>N_{\text {upsift }}
$$

Downshift - Operating point goes before downshift speed $N_{\text {downshift }}$

$$
N_{\text {eng }} \leq N_{\text {downshift }}
$$

Down shift - Operating point goes downshift torque $T_{\text {downshift }}$

$$
T_{\text {eng }} \geq T_{\text {downshift }}
$$

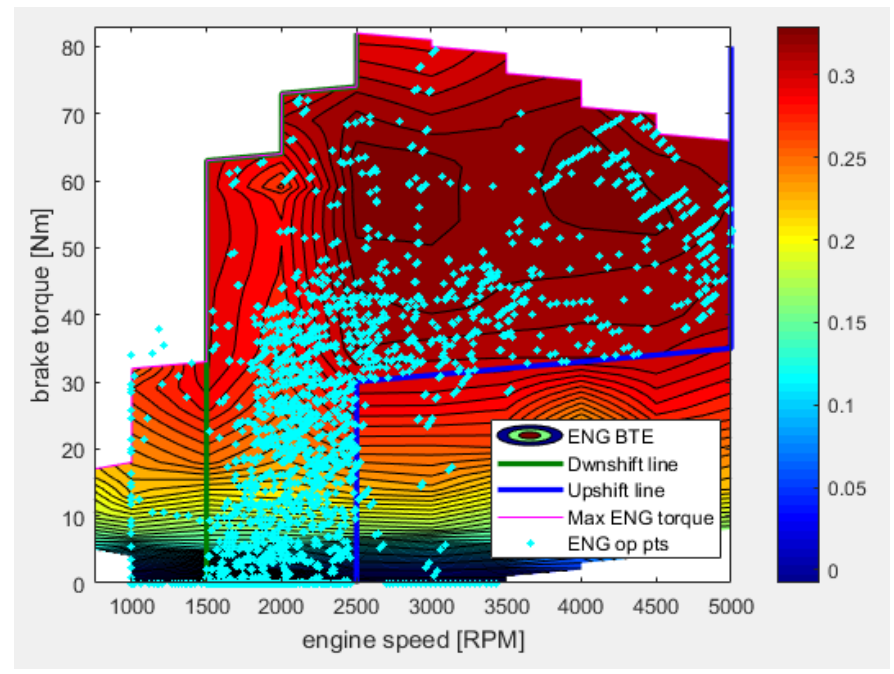

Fig. 2. Engine operating points - fixed gear shift strategy 
Fig. 2 shows operating points for the combustion engine fall well within the desired region when the vehicle is running on the WLTC cycle with the tuned fixed gear shift strategy. Some points lie outside the selected area as the gear shift strategy is limited by the lowest [1] and highest [6] gear apart from the engine constraints discussed earlier.

$$
G_{\text {select }}=[1: 6]
$$

When wheel speed is plotted against engine speed (Fig. 3), the operating points for our cycle follow straight lines whose slopes correspond to the gear ratios [1:6] of the transmission. This along with the engine brake thermal efficiency BTE map (Fig. 2) gives an idea about how the tuned shift strategy affects the spread and usage of the engine operation over the various possible gear selections for achieving better fuel efficiency.

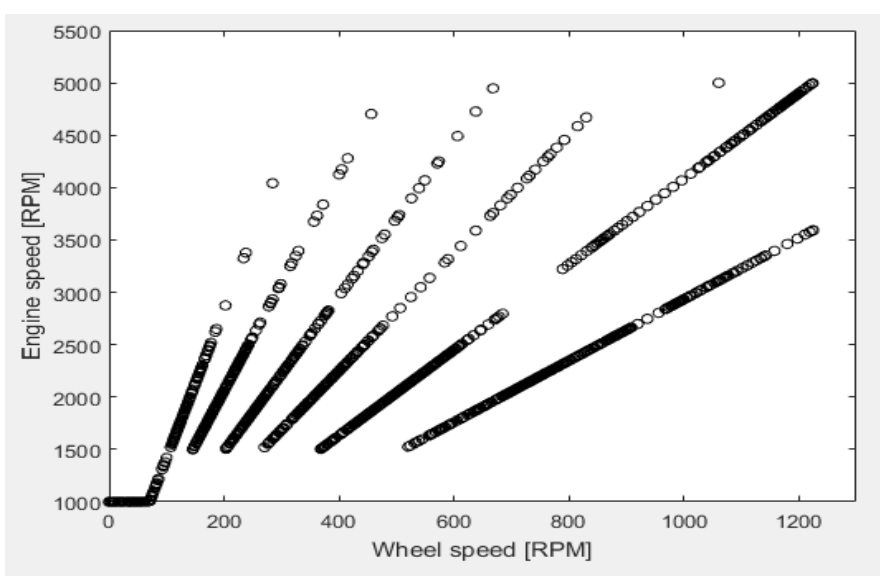

Fig. 3. Wheel speed vs engine speed - fixed gear shift strategy

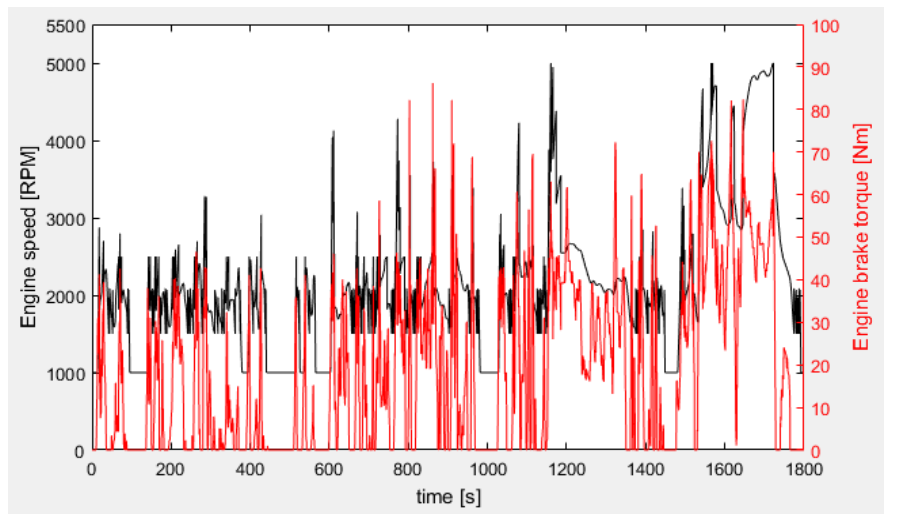

Fig. 4. Engine speed and brake torque - fixed gear shift

Fig. 4 shows engine brake torque and speed for the WLTC cycle following the tuned fixed gear shift strategy and also complying with the engine operation limits proving that our model functions well within the powertrain constraints.

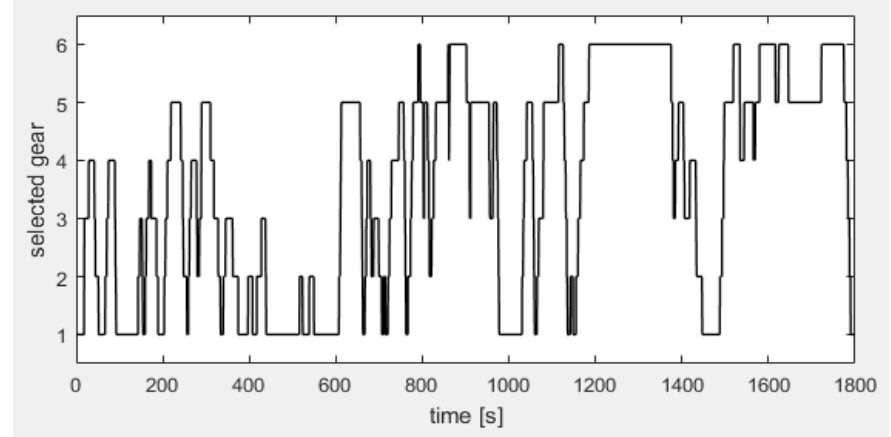

Fig. 5. Gear selection - fixed gear shift strategy

The corresponding gear selection followed by the gearbox control is shown in Fig. 5.

\section{B. Optimal gear shift strategy}

To further increase the possible overall powertrain efficiency through even better utilization of the combustion engine, the ideal optimal gear shift strategy was considered for the best possible placement of engine operating points while still respecting constraints of the combustion engine and the available gears.

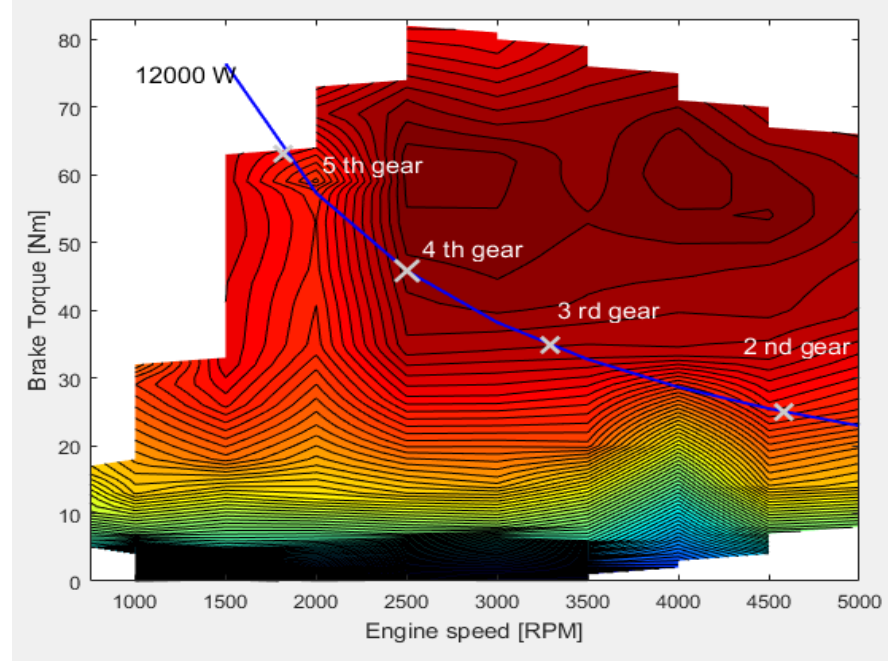

Fig. 6. Gear choice in optimal shift strategy

The idea behind this optimal gear shift strategy is to compare the engine efficiencies corresponding to all feasible gear selections at any instant and then choosing the gear with the highest corresponding efficiency $\eta_{\text {eng }} g_{B T E m a x}$. This will in the ideal case assure overall highest efficiency of engine operation throughout the driving cycle. 


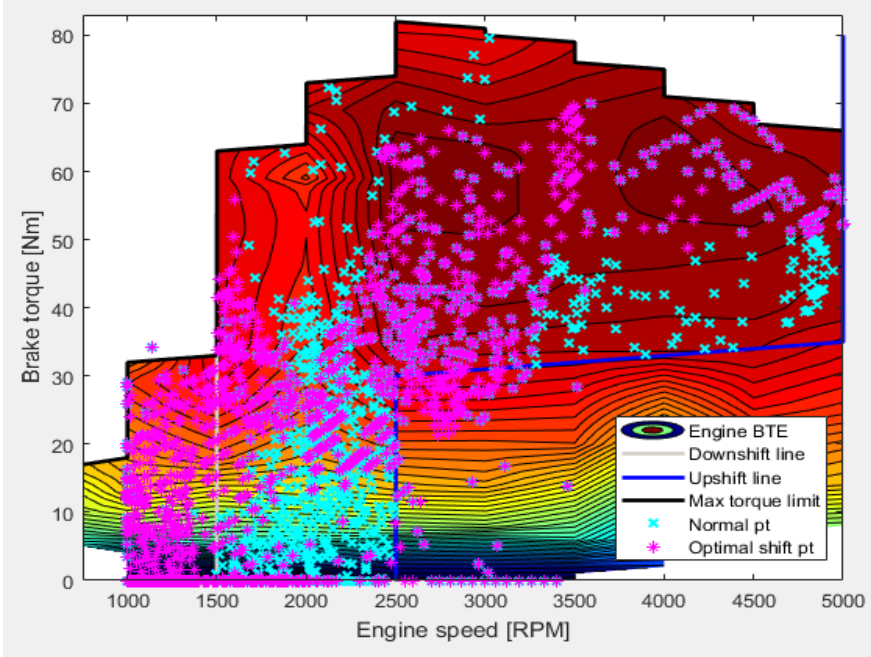

Fig. 7. Engine operating points - fixed vs optimal gear shift strategy

By comparing engine operating points for previous fixed (cyan) and optimal gear shift strategy (pink) on the brake thermal efficiency map (Fig. 7) it can be seen that for the optimal selection case they tend to be differently and more ideally placed, showing that the second case tends to better avoid operation in inefficient zones.

Plotting operating points for optimal shift and fixed shift on wheel speed vs engine speed graph (Fig. 8) further shows that for every gear selection, the engine is being used differently with some points being overlapped.

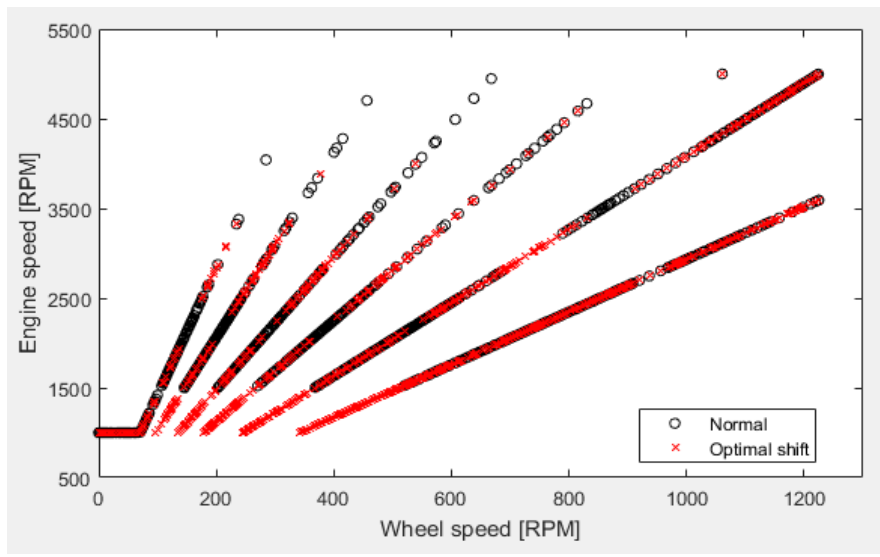

Fig. 8. Wheel vs engine speed - fixed and optimal gear shift strategy operation

Optimal shift is safety assured while still following safety laws which are superimposed over the choice of the gear,

Upshift if

$$
N_{\text {eng }} \geq N_{\text {eng_max }}
$$

Downshift if

$$
N_{\text {eng }}<N_{\text {eng_min }} \| T_{\text {eng }} \geq T_{\text {eng_max }}
$$

$$
\begin{gathered}
G_{\text {select }}=[1: 6] \\
G_{\text {select }}=f\left(\eta_{\text {eng } \left.g_{B T E \max }\left(G_{1}: G_{6}\right)\right)}\right.
\end{gathered}
$$

In general, for this case, the optimal shift strategy tends to avoid high-speed, low load operation in lower gears by shifting into the next gears earlier for the first three gears and transfers it to low/medium speed points for the higher gears (Fig. 9, Fig. 10, Fig. 11).

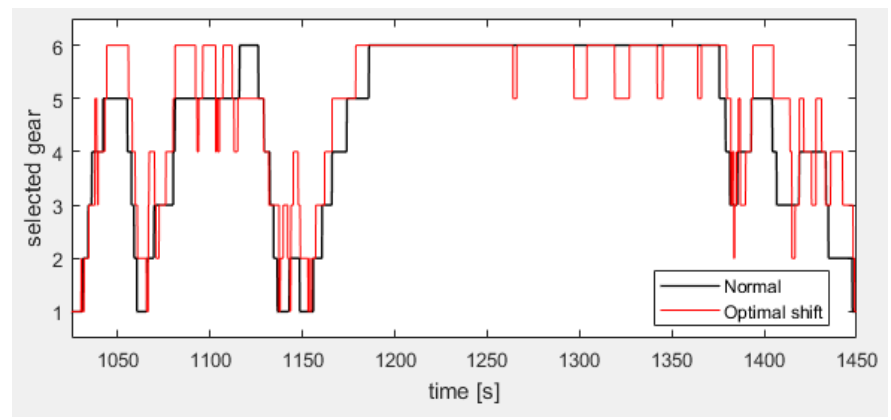

Fig. 9. gear selection - fixed and optimal gear shift strategy

When comparing in detail $(1025 \mathrm{~s}-1450 \mathrm{~s})$ the gear selections for fixed shift and optimal shift for a part of the WLTC cycle, it can be observed that although the two strategies follow a similar trend in their shifting to respect engine operation constraints, the optimal shift (red) takes a significantly different path to make the engine run at slightly higher efficiency and reduce a bit of fuel consumption, whose cumulative effect for the complete cycle is found to be substantial.

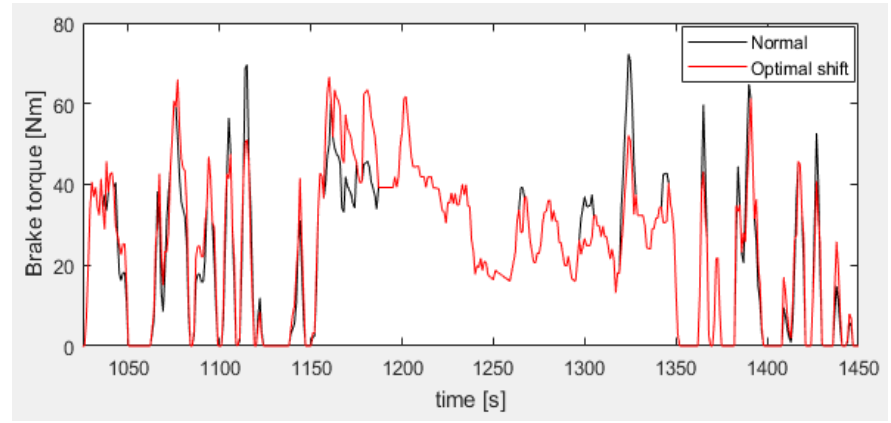

Fig. 10. Engine brake torque - fixed, optimal gear shift strategy

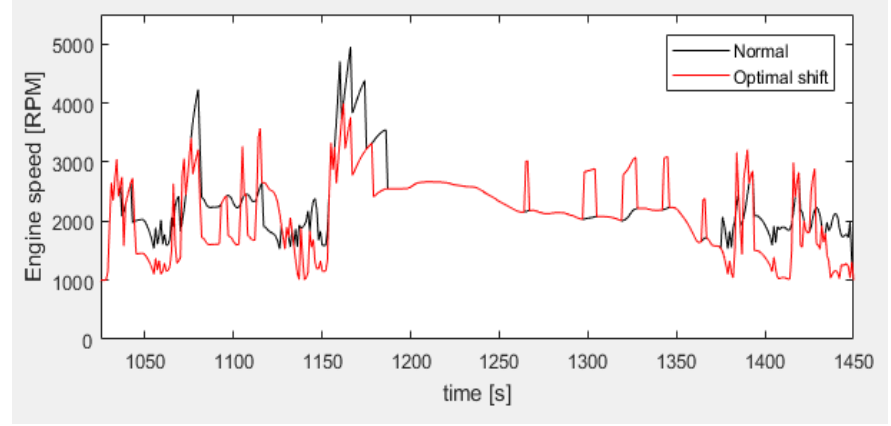

Fig. 11. Engine speed - fixed, optimal gear shift strategy 
The corresponding effect of this gear selection on brake torque and engine speed can be seen for the same driving cycle interval.

\section{Start - stop and coasting}

In the start-stop strategy, the combustion engine is shut off when not in use if the vehicle is stationary. This avoids the engine working against its internal friction and auxiliaries, saving the energy that would otherwise be wasted to maintain the engine operation at idle speed.

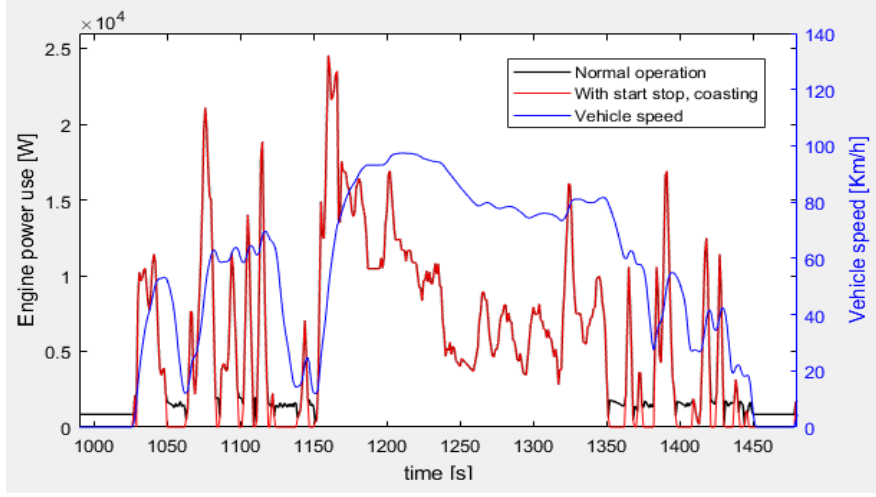

Fig. 12. Engine power used - normal and start stop coasting active

The coasting strategy involves cutting off fuel flow to the engine when the vehicle is moving and the load demand gets equal to or below zero. These situations arise when the driver leaves the accelerator pedal and the vehicle decelerates. By conserving fuel when the engine does not produce any torque using these two methods, the overall fuel saving over the complete driving cycle can be significantly improved.

For detailed study of effect of start-stop and coasting strategy the cycle part (990s - 1480s) is shown.

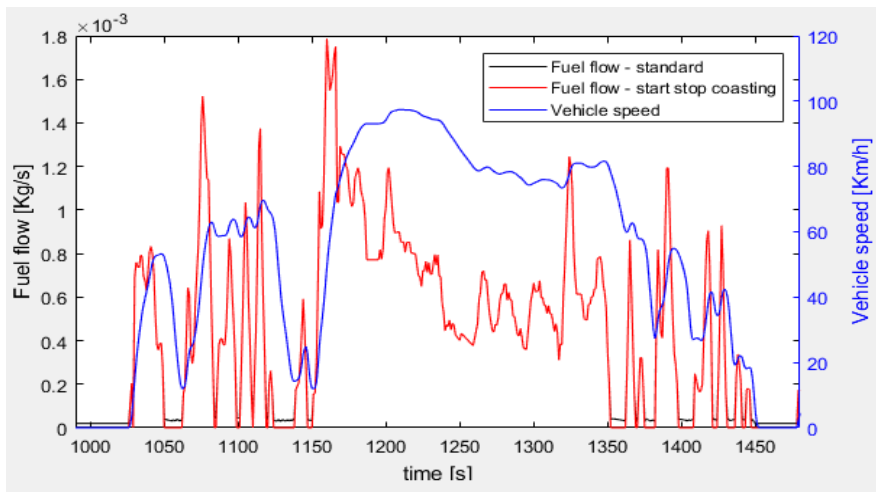

Fig. 13. Engine fuel flow for normal and start stop coasting active

It can be seen from Fig. 12 and Fig. 13 that the fuel usage is avoided in parts of the driving cycle where the engine load demand is zero or negative such as for deceleration or standstill conditions leading to better overall fuel economy.

\section{Continuously variable transmission CVT}

A continuously variable transmission can ideally provide any desired gear ratio within its physical limits and vary it continuously during the functioning of the powertrain according to the control strategy to provide the best engine operation for desired results. When chasing powertrain efficiency, control of the CVT involves choosing the gear ratios at any instance in such a way that the engine operation will closely follow the optimal power profile on its BTE map to give the highest possible engine efficiency at any demand throughout its power range leading to ideally a cumulative gain over the complete driving cycle.

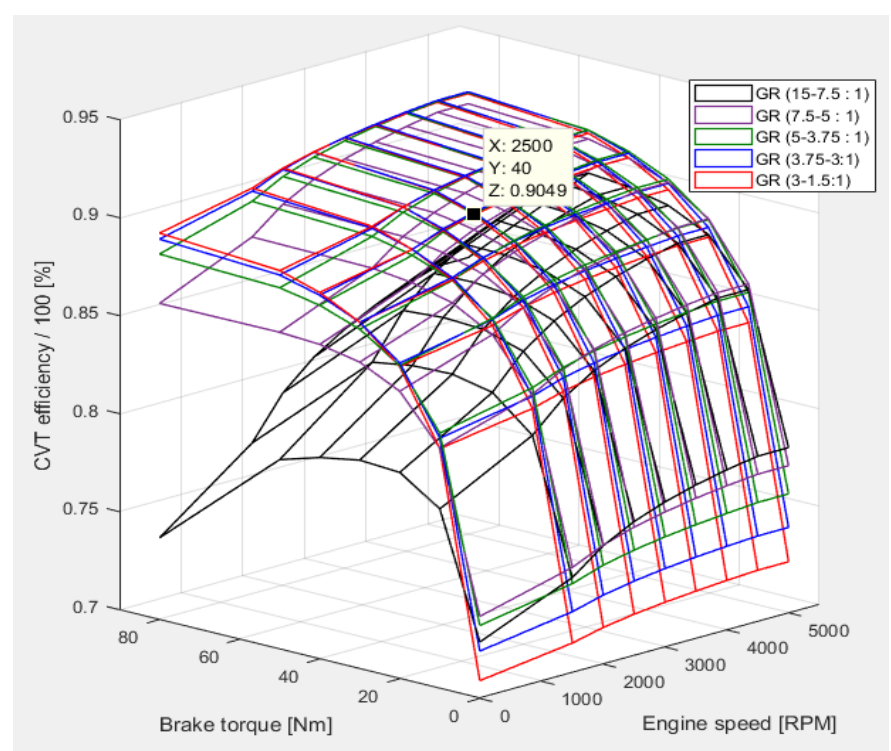

Fig. 14. CVT gearbox efficiency map for different gear ratios

Although the CVT is very effective at maintaining engine efficiency it has drawbacks in terms of its own transmission efficiency. In our case where the conventional gear box is assumed to have $94 \%$ fixed transmission efficiency (three gear reductions in series), the efficiency of a CVT is found to fluctuate between $70 \%$ - $92.5 \%$ as assumed in our case depending on its operation. Fig. 14 shows the CVT transmission efficiency maps for varying gear ratios, prime mover speed and torque taken from ADVISOR open source software [11]. It is evident that within the operating range, using of more aggressive gear ratios and lower speed, torque the transmission efficiency worsens.

Thus application of a CVT transmission for increasing powertrain efficiency is based on how the compromise between efficiency gain in the combustion engine operation and loss in power transmission is balanced with respect to the specific powertrain application, operating conditions and vehicle characteristics. Thus, in certain applications it may or may not be advantageous to use the CVT as can be seen in later parts of this paper. 


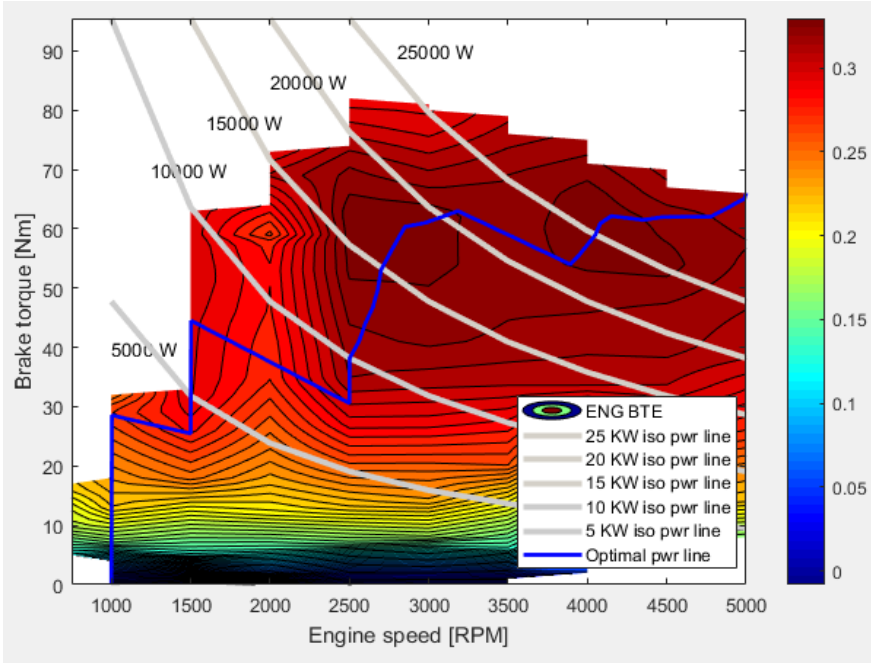

Fig. 15. Engine optimal power line calculation

For CVT control, the optimal power line (blue) is made on the engine BTE map by connecting the most efficient operating points at each power level (iso - power lines grey) for the complete power range as can be seen in Fig. 15. Then by following the optimal power line for the power demand in engine operation the corresponding engine torque or speed one can be found out. This instantaneous required torque $T_{\text {eng_opl }}$ or speed $N_{\text {eng }}$ opl along with the wheel torque or speed can give us the needed gear ratio $G R_{C V T}$ to follow the optimal power line. This gear ratio when inside the possible working range of the CVT can be ideally directly used in the functioning or when outside, the corresponding CVT gear ratio limit can be used.

$$
P_{\text {eng }}=\left[0: P_{\text {eng_max }}\right]
$$

From optimal power line calculation,

$$
N_{\text {eng opl }}=f\left(P_{\text {eng }}, \eta_{\text {eng_BTE }}\right)
$$

CVT total gear ratio range is considered to be between,

$$
\text { [1.5:1 - 15:1] }
$$

$$
\begin{gathered}
G R_{C V T}=\frac{T_{\text {trns }}}{\eta_{\text {trns }}\left(T_{\text {eng_opl }}-J_{\text {eng }} \frac{d \omega_{\text {eng }}}{d t}\right)} \\
G R_{C V T}=\frac{N_{\text {eng_opl }}}{N_{\text {trns }}}
\end{gathered}
$$

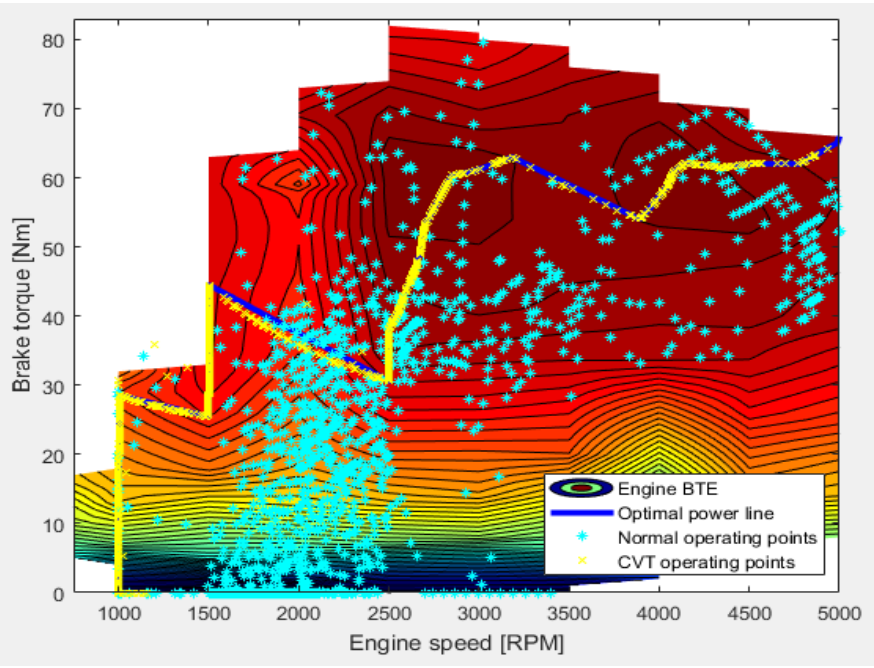

Fig. 16. Engine operating points: fixed gear shift and CVT

Fig. 16 shows the optimal power line (blue) and the operating points for CVT application (yellow) in comparison to those for conventional fixed strategy (cyan) on the WLTC for our application.

It can be seen that the CVT makes the engine operating points in most cases follow the optimal power line except for some zones where the gear ratio limits do not allow the exact but close to desired operation.

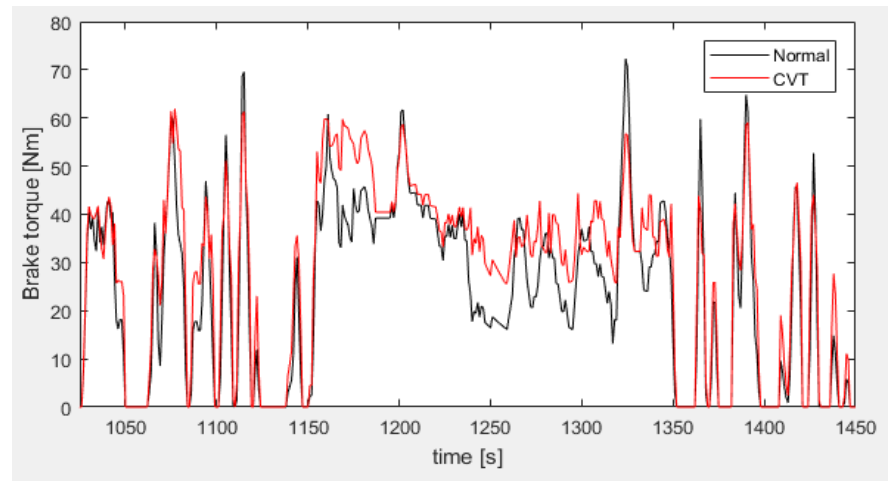

Fig. 17. Engine brake torque - fixed shift strategy and CVT

From a more detailed view of the WLTC operation (1025s - 1450s) in Fig. 17, Fig. 18 it can be seen that the CVT offers much more unrestrained functioning against fluctuating power demands by freely manipulating the brake torque and engine speed in order to make the operating points follow the optimal power line and thus aiming for highly efficient use of the prime mover. 


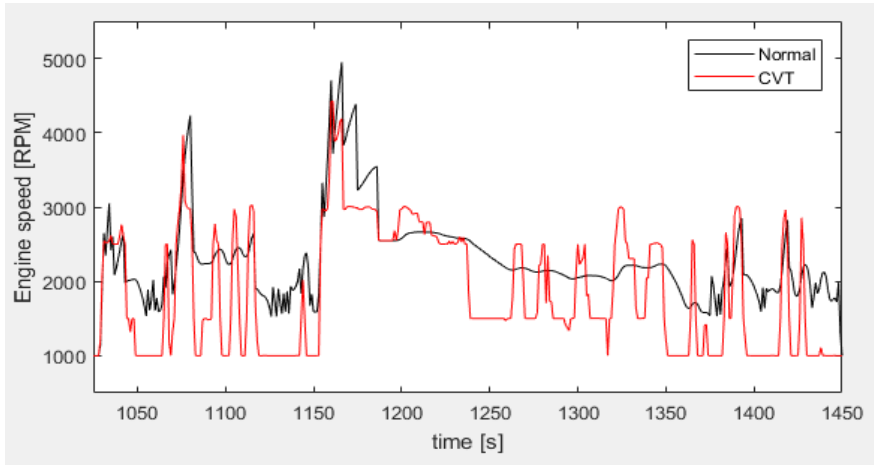

Fig. 18. Engine speed - fixed shift strategy and CVT

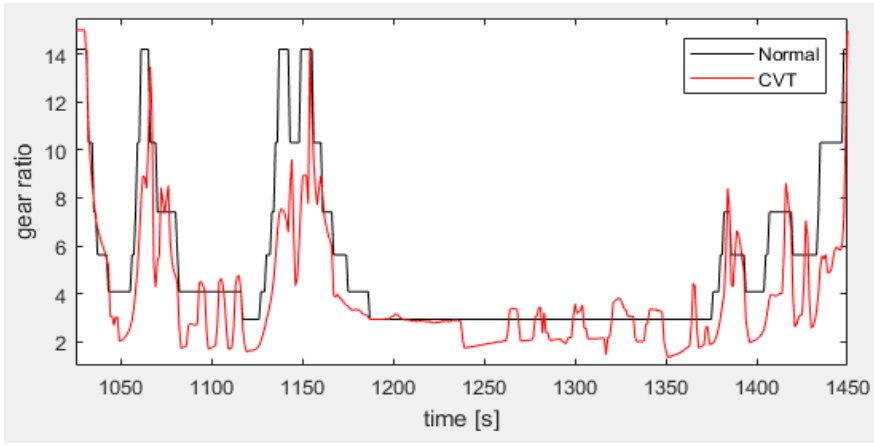

Fig. 19. Gear ratio - fixed gear shift strategy and CVT

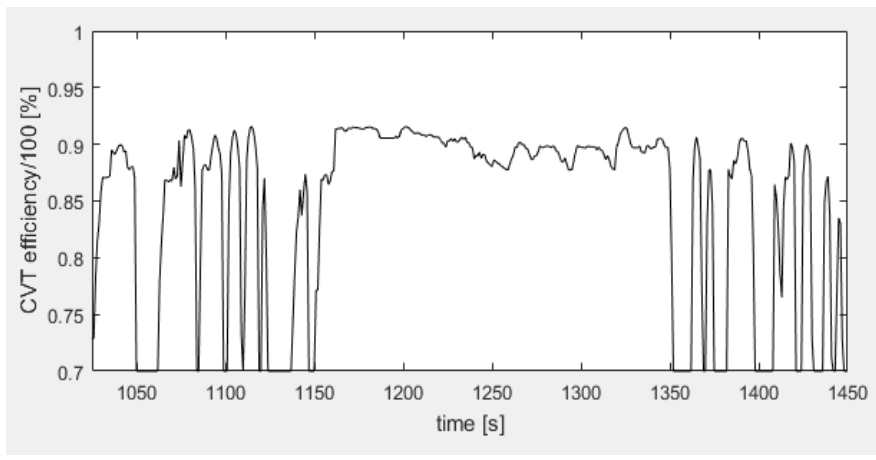

Fig. 20. CVT gearbox efficiency for WLTC cycle

This can be further verified by viewing the selection of gear ratios by the CVT in Fig. 19. The conventional gearbox is limited by six fixed gear ratios and is thus making a compromise in selecting the best amongst the available to keep the engine working in the desired zone. The conventional transmission in comparison to the CVT is not directly controlled by power demand but instead by the instantaneous engine operating torque and speed. Thus, even with slight changes in power demand the CVT can adjust the gear ratio to maintain efficient operation as can be seen in the zone (1200s 1350s) where the conventional is fixed on one gear ratio and the CVT is still continuously adjusting the ratio the get the best operation. Fig. 20 shows the corresponding CVT transmission efficiency in that part of the driving cycle.

\section{E. Fuel efficiency analysis}

Fig. 21 compares the cumulative fuel consumption for normal with the fixed shift, optimal gear shift strategy, and
CVT application without and with the implementation of startstop and coasting strategies throughout the WLTC cycle.

$T A B L E 2$ shows final results for fuel economy comparison of the above-discussed cases along with the $\mathrm{CO} 2$ emission and comparative percentage advantage over the standard powertrain. The fuel economy simulation results for standard powertrain close to real claims [13] confirms precision of our simulation.

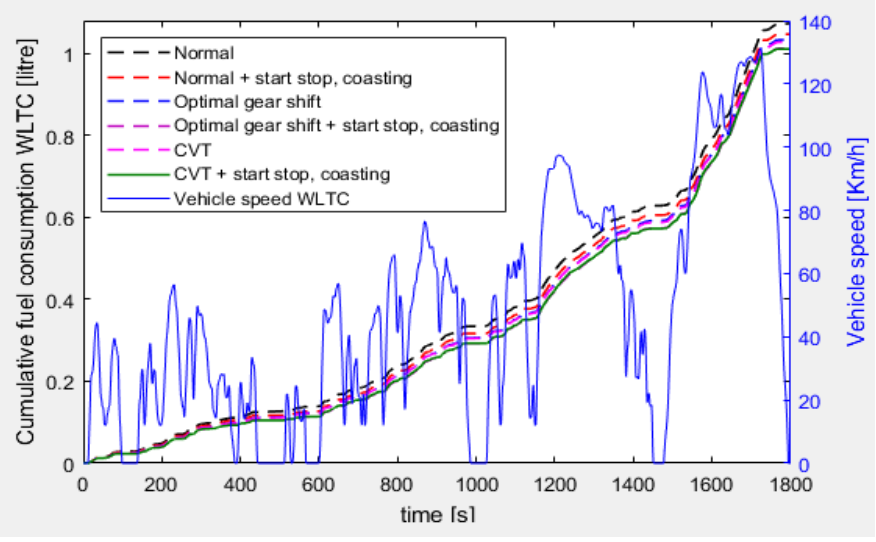

Fig. 21. Cumulative fuel consumption WLTC

TABLE 2 FUEL ECONOMY COMPARISON

\begin{tabular}{|l|l|l|l|}
\hline \multicolumn{1}{|c|}{ Strategy } & $\begin{array}{c}\text { Fuel } \\
\text { economy } \\
{[\text { l/100km] }}\end{array}$ & $\begin{array}{c}\text { Percent \% } \\
\text { improvement on } \\
\text { standard }\end{array}$ & $\begin{array}{c}\text { CO2 } \\
{[\mathbf{g} / \mathbf{K m}]}\end{array}$ \\
\hline Fixed gear shift strategy & 4.613 & - & 106.7 \\
\hline start stop and coasting & 4.5 & $2.449 \%$ & 104.1 \\
\hline Optimal gear shift strategy & 4.444 & $3.663 \%$ & 102.8 \\
\hline $\begin{array}{l}\text { Optimal gear shift strategy }+ \\
\text { start stop and coasting }\end{array}$ & 4.351 & $5.679 \%$ & 100.7 \\
\hline CVT & 4.42 & $4.183 \%$ & 102.3 \\
\hline CVT + start stop and coasting & 4.347 & $5.766 \%$ & 100.6 \\
\hline
\end{tabular}

\section{F. $48 v$ mild hybridization}

48-volt mild hybridization was considered a major part of this study as an effective technique in increasing fuel efficiency at significantly humble costs. Like most hybrid systems, the mild hybrid offers possibilities electric-only mode operation inside its power limits, energy recuperation through regenerative braking and energy storage, and electric support to the main prime mover for efficient functioning with the intension od making better use of the complete powertrain by avoiding low-efficiency engine operation and reusing of the energy lost in braking. A $48 \mathrm{v}$ hybrid system uses an electrical system designed to work at nominal 48 volts consisting of an electric drive, power electronics, and a battery. The main advantage of a 48-volt hybrid system over others is that the increased nominal operating voltage allows handling much higher power demands as compared to a 12-volt system while still remaining cost and weight effective in comparison to the expensive high voltage full hybrid systems [3], [10]. To analyze the functional effect of the range of possible hybrid architectures [7] in combination with the above-discussed gearbox configurations, in all we P2 and P4 parallel hybrid architectures with the original transmission (fixed gear shift) and continuously variable transmission (CVT) respectively. 
In this study, a standard electric motor and battery unit that is readily available in the market was considered (TABLE 5). Fixed electric motor (8KW) and battery size (384Wh) [6] was used for our four scenarios with the possible calibration of only one tuning factor: $P_{\text {switch }}$ the traction power demand switch point above which the powertrain operation goes from electric traction to combustion engine traction mode. Optimization of electric motor, battery size and application of electric boost mode were not considered a part of this study to keep it simpler and to easily understand the effect of different architectures although these are sure methods for further achieving even better utilization and efficiency of the powertrain.

With the objective of studying and comparing the effect of different architectures and as the developed models used were quasi-static in nature, the control of the hybrid system was done using simple rule-based strategy [3]. The strategy involves activating hybrid system function modes according to the power demand of the vehicle instead of torque demand which is justified as the models used are backward quasi-static in nature and do not consider dynamic effects.

TABLE 3 HYBRID SYSTEM CONTROL STRATEGY

\begin{tabular}{|c|c|c|}
\hline Value & Hybrid mode & Activation condition \\
\hline 1 & Static & $\begin{array}{c}\text { Vehicle is stationary } \\
P_{w}=0\end{array}$ \\
\hline 2 & Electric & $\begin{array}{r}\text { Vehicle runs on electric power } \\
P_{\text {switch }}>P_{w}>0\end{array}$ \\
\hline 3 & Engine & $\begin{array}{c}\text { Vehicle runs on combustion engine } \\
P_{w}>P_{\text {switch }}\end{array}$ \\
\hline 4 & $\begin{array}{c}\text { Regenerative } \\
\text { braking }\end{array}$ & $\begin{array}{c}\text { Braking power recuperation for } \\
\text { further use by the electric powertrain } \\
P_{w}<0\end{array}$ \\
\hline 5 & $\begin{array}{c}\text { Static } \\
\text { charging }\end{array}$ & $\begin{array}{c}\text { Vehicle is coasting / decelerating / } \\
\text { stationary } \\
P_{w}=0 \& \text { SOC }<35 \% \text { until SOC }> \\
65 \%\end{array}$ \\
\hline 6 & $\begin{array}{c}\text { Dynamic } \\
\text { charging }\end{array}$ & $\begin{array}{c}\text { Vehicle is running } \\
P_{\text {chrg_max }}>P_{w}>0 \text { \& SOC }<30 \% \\
\text { until SOC }>70 \%\end{array}$ \\
\hline
\end{tabular}

When the vehicle starts to move or if the vehicle needs a small amount of power to move, the electric motor is used in electric mode $\{2\}$ instead of the combustion engine to power the traction which helps in avoiding combustion engine operation in the low power, low-efficiency zones. The electric mode can be used if it is possible to run the motor inside its limits of speed, torque, and power output.

When the vehicle needs higher power to meet desired speed or acceleration objectives, the combustion engine $\{3\}$ is used if it operates in an efficient zone or if the power demand is outside the electric motor operating limits.

When braking, the regenerative mode $\{4\}$ is used to recuperate the kinetic energy of the moving vehicle weight using the electrical part of the hybrid powertrain which is then stored in the battery for later use in electric mode $\{2\}$. The energy recuperation is limited by the power limit, torque limit and speed limit of the electric drive although using a set of gears can help in overcoming torque and speed limits.

When the battery discharges below a certain state of charge (SOC) the combustion engine and electric motor combination is used to charge the battery to the desired level. If the vehicle needs zero power to meet its speed objective or if the vehicle is stationary the static charging mode $\{5\}$ is used. If the vehicle needs power to run and the battery needs charging, the dynamic charging mode $\{6\}$ is used where the combustion engine supports both the traction and battery charging. This is kept possible only under a certain maximum level of traction power demand $P_{\text {chrg_max }}$ above which the vehicle is run using solely the combustion engine $\{3\}$.

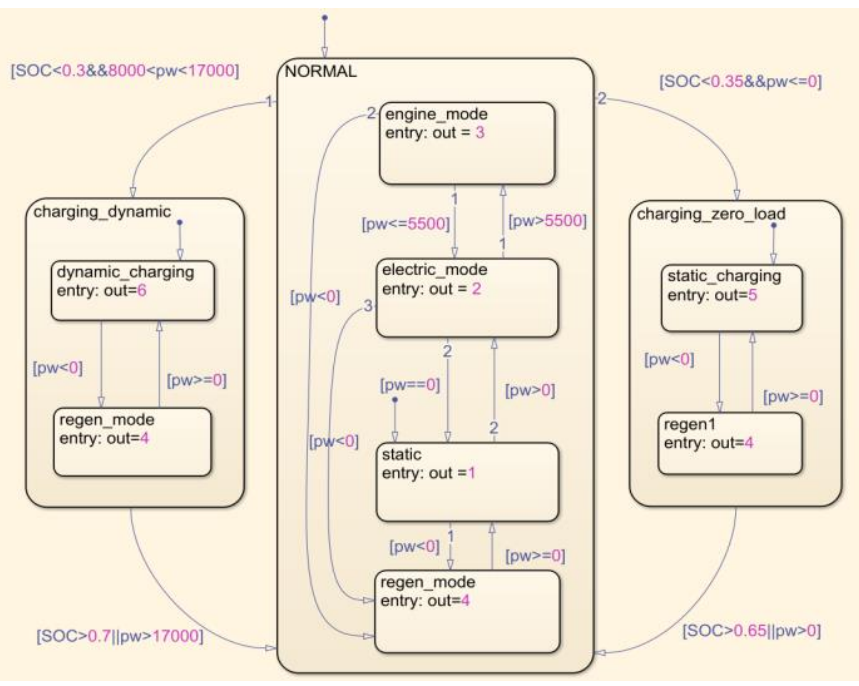

Fig. 22. State flow for rule based hybrid control strategy

Measuring fuel consumption for a hybrid powertrain can be complicated over a single driving cycle as the cumulative change in battery state of charge (SOC) during the cycle has to be taken into account in terms of fuel consumption. Some techniques use control strategies in which it is made sure that the SOC reaches close to its initial cycle start value at the driving cycle end by charging. Another way used by us is to run the driving cycle again and again until the SOC reaches its initial value from the start of the test. However, taking the final measurement in such a way may not consider an equal impact of the whole driving cycle evenly (urban and highway running parts). To minimize this error, the WLTC cycle was run for 4 consecutive times $(93 \mathrm{~km})$ with respect to our small battery size and fuel economy was considered from the point near the end of these cycles when the SOC would reach its initial value.

\section{1) P2 hybrid}

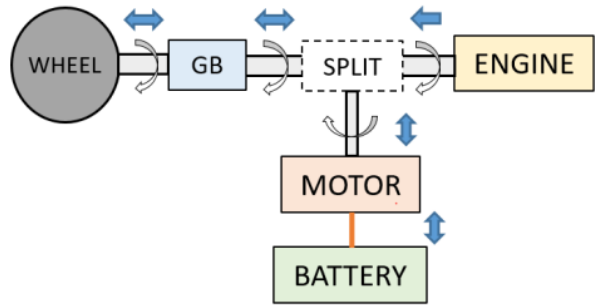

Fig. 23. P2 hybrid powertrain architecture

Starting with the currently most used architecture, P2 hybrid involves placing an electric motor between the combustion engine and the gearbox. Thus, the transmission can be put 
towards better use of both the prime movers (electric motor and engine) similar to what it could do in a conventional application for the combustion engine.

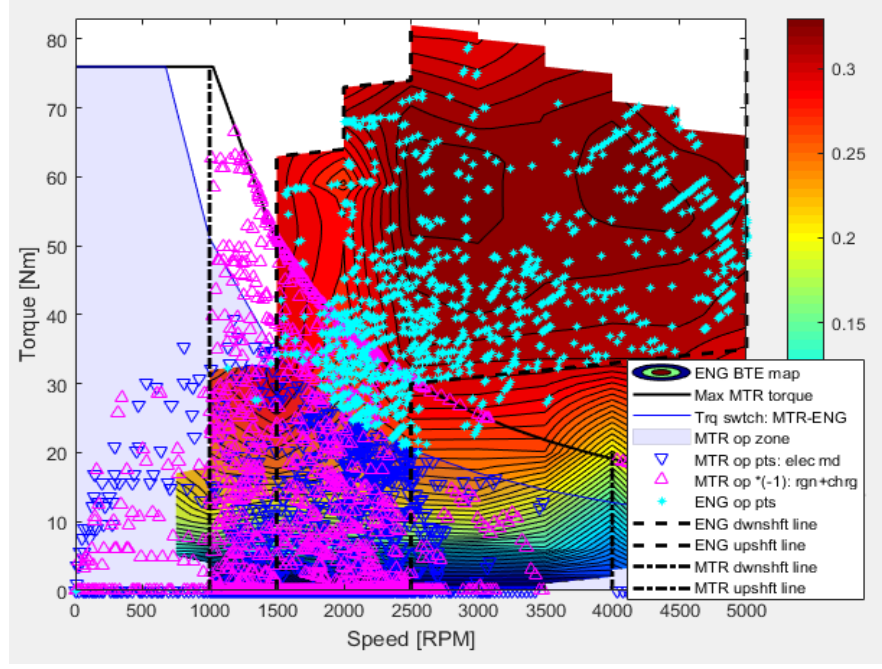

Fig. 24. Engine operating points for P2 on WLTC

Fig. 24 shows the engine (cyan) and motor operating points for traction (blue) and motor charging + regenerative braking (pink) for and their respective gear upshift - downshift strategy lines used for controlling the transmission. The max motor torque line (black) shows the maximum possible output of the electric motor with respect to the engine. The motor operation zone (blue) shows the selected, calibrated region of output (optimal $P_{\text {switch }}=5350 \mathrm{~W}$ ) for the combined powertrain to get the best overall fuel efficiency over consecutive driving cycles.

Operating points for electric motor are shown in detail in Fig. 25 for traction mode (blue), regeneration mode (pink), static (grey), and dynamic (yellow) charging mode along with gear shift strategy (upshift and downshift). It can be seen that with the possibility of using the gearbox for the electric motor in the P2 setup, better placement of motor operating points is possible for most cases by avoiding inefficient operation zones.

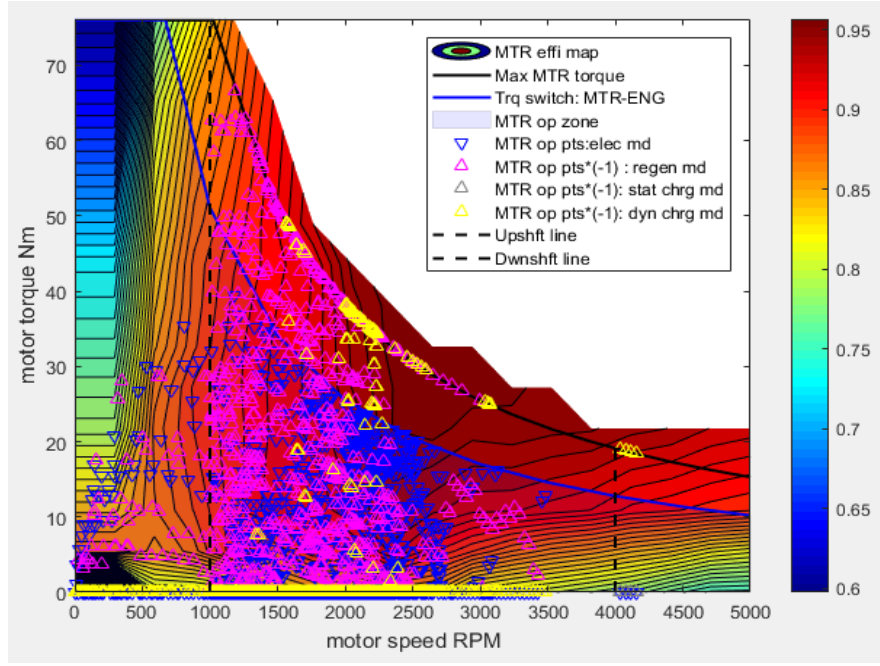

Fig. 25. Motor operating points for P2 on WLTC

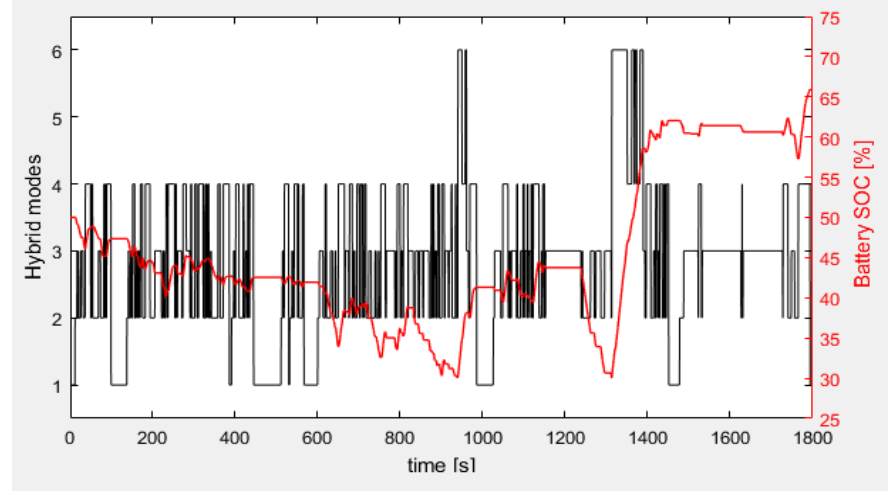

Fig. 26. Battery SOC for P2 on WLTC

Fig. 26 shows that the $\mathrm{P} 2$ architecture with selected optimal $P_{\text {switch }}=5350 \mathrm{~W}$ calibration can properly charge the battery by using simply dynamic charging mode whose operating zones can be seen in Fig. 25 (yellow).

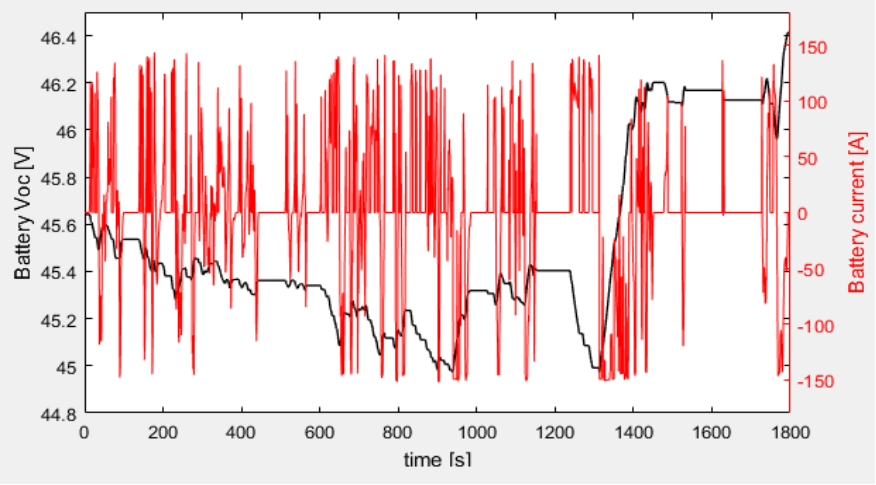

Fig. 27. Battery Voc and I bat for P2 on WLTC

Fig. 27 shows the battery open circuit voltage $V_{o c}$ and current $I_{b a t}$ variation for corresponding SOC change to support electric drive operation for P2 on WLTC cycle. With discharge the $V_{o c}$ decreases and with charge increases. Positive current shows discharging and negative shows charging.

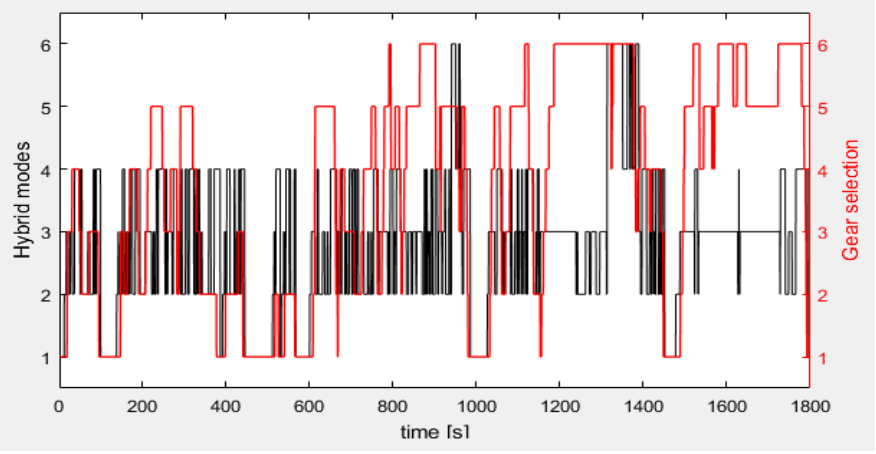

Fig. 28. Gear selection for P2 on WLTC

When studying gear selection and hybrid modes for WLTC cycle in Fig. 28 it can be seen that the shift strategy operates smoothly while considering shift needs for both electric motor and engine depending on the activated mode (comparing with Fig. 5). 
2) $P$ 2 hybrid $+C V T$

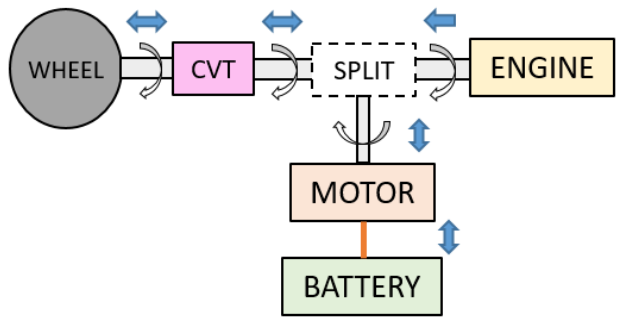

Fig. 29. P2 hybrid powertrain architecture with CVT

In this setup, for P2 architecture the conventional transmission with fixed shift strategy was replaced by a continuously variable transmission CVT with optimal power line based control (discussed earlier in Fig. 15) for both the combustion engine and electric motor operation.

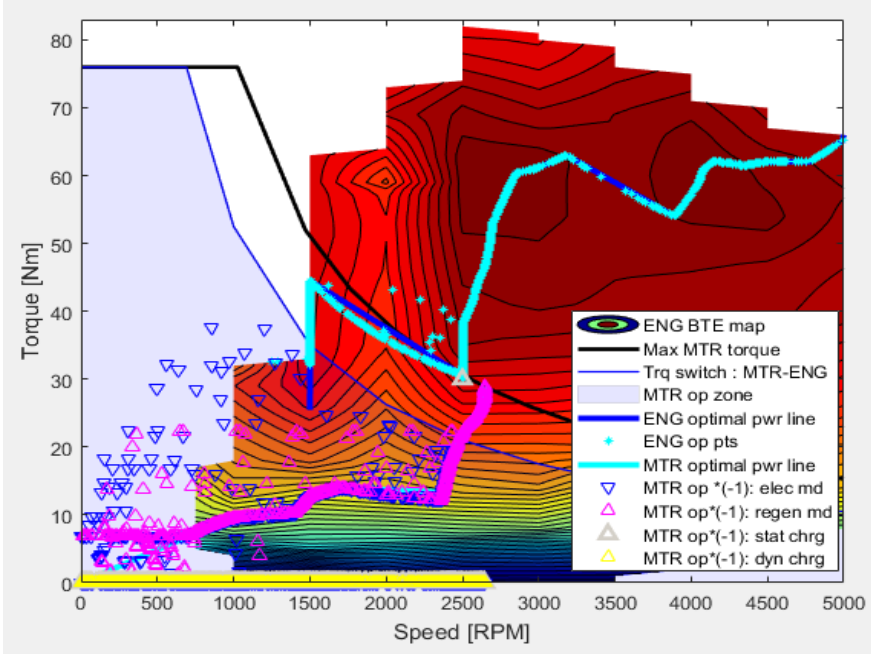

Fig. 30. Engine operating points for P2 + CVT on WLTC

Fig. 30 shows the operating points for the combustion engine (cyan) and electric motor in traction, regenerative braking, and charging conditions. The max output of the electric motor and the selected motor traction operating zone for optimal $P_{\text {switch }}=5050 \mathrm{~W}$ is also shown. It can be seen that for the combustion engine most operating points closely follow the optimal power line although limited by the gear ratio range of the CVT.

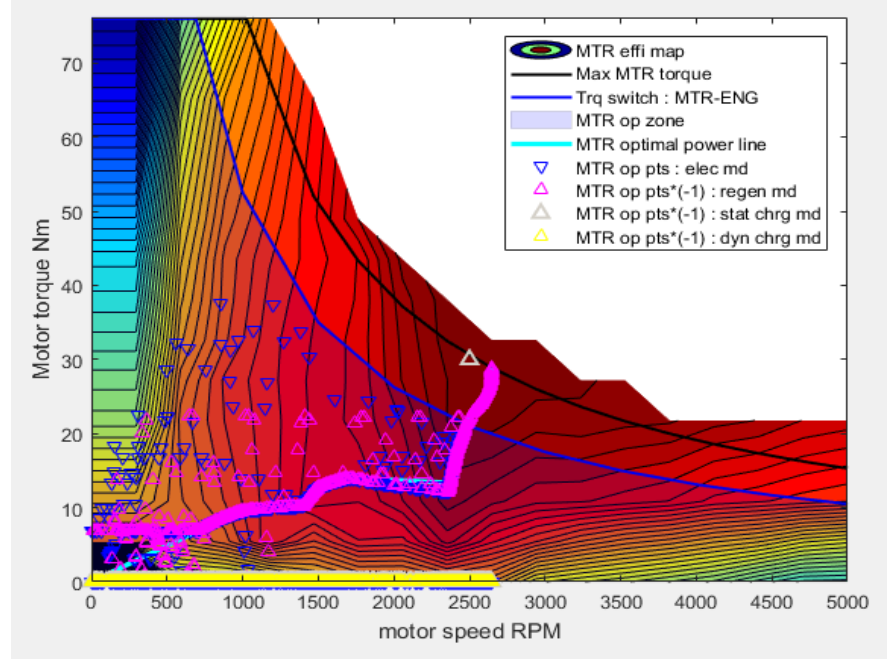

Fig. 31. Motor operating points for P2 + CVT on WLTC

Fig. 31 shows that the effect of the CVT gear ratio limits is more evident in case of electric motor operating points for traction (blue) and regenerative braking (pink) in which not all points are able to follow the optimal electric power line (cyan). This can be understood by the fact that as the electric motor is used in more drastic conditions such vehicle launch, low-speed operation, and braking, the operation has to be done in a large variation of motor torque and speed with respect to wheel torque and speed. For this very tall or short gear ratios are needed which are outside the limits of the CVT leading to some points falling outside the desired region.

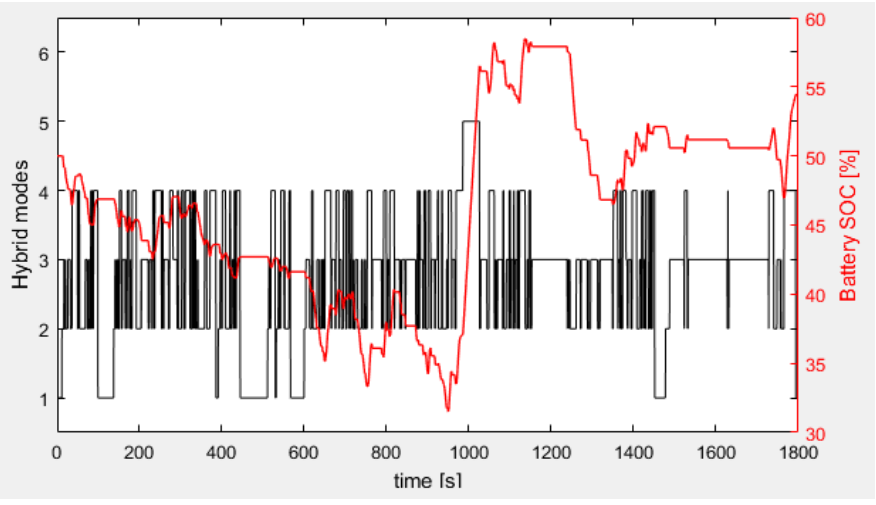

Fig. 32. Battery SOC for P2 + CVT on WLTC

It can be seen in Fig. 32 that the P 2 CVT setup with selected optimal $P_{\text {switch }}=5050 \mathrm{~W}$ calibration can properly charge the battery by using static charging mode whose operating points can also be seen in Fig. 31 (grey). 


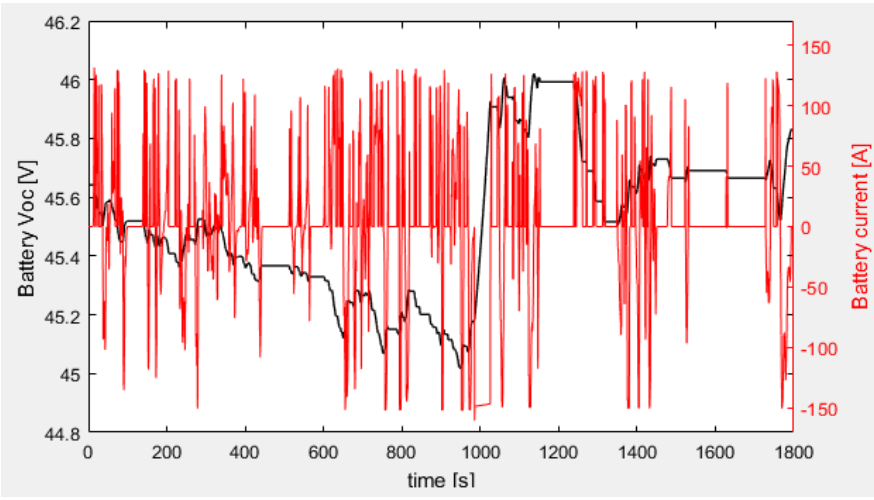

Fig. 33. Battery Voc and I bat for P2 + CVT on WLTC

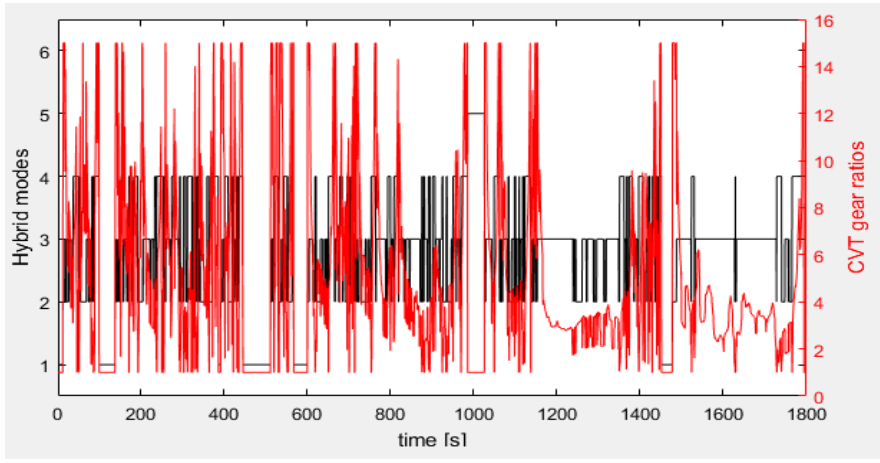

Fig. 34. CVT gear ratios for P2 + CVT on WLTC

From Fig. 34 it is observed that the CVT transmission provides gear ratios to optimally place operating points of both electric motor in mode 2 (high ratios) and combustion engine mode 3 (lower ratios).

3) P4 hybrid

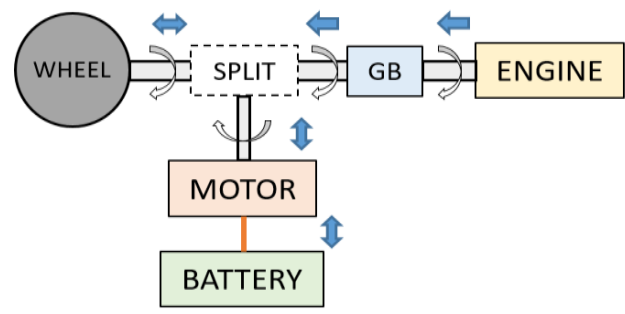

Fig. 35. P4 hybrid powertrain architecture

In the P4 type architecture, the motor is attached between the transmission and wheels on the axle with the advantages of avoiding transmission losses in traction and regenerative braking. The clear disadvantage is limitation in using the electric motor for drastic operating points (heavy launch and braking) inside its power range when surpassing torque or speed limit. Another drawback is lower efficiency in battery charging due to transmission losses between the engine and the electric motor. To better fit the electric motor operation for allowing wider traction and regeneration usage implementation of a single tuned gear reduction (4.8:1) (2\% loss) was done between the wheels and electric motor.

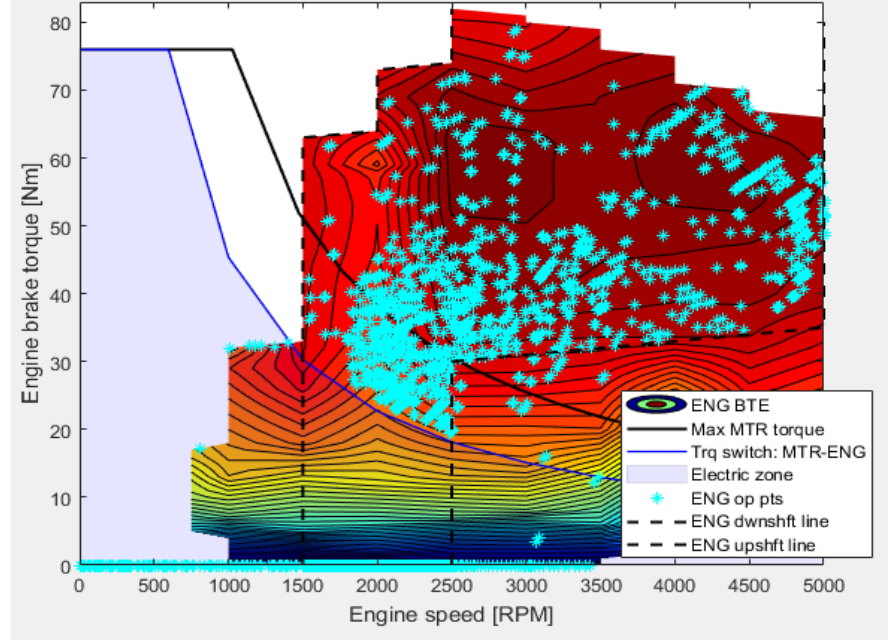

Fig. 36. Engine operating points for P4 on WLTC

Fig. 36 shows the tuned switch point $=4750 \mathrm{~W}$ (blue) at which the powertrain switches from electric operation to engine use which is found to give the maximum fuel efficiency over consecutive cycles. It can be seen that using the original fixed gear shift strategy, the combustion engine operating points (cyan) fall mostly in the desired high-efficiency region except for some falling in the much lower areas of expected electric operation as the electric motor is not able to replace those points due to crossing of its torque or speed limits.

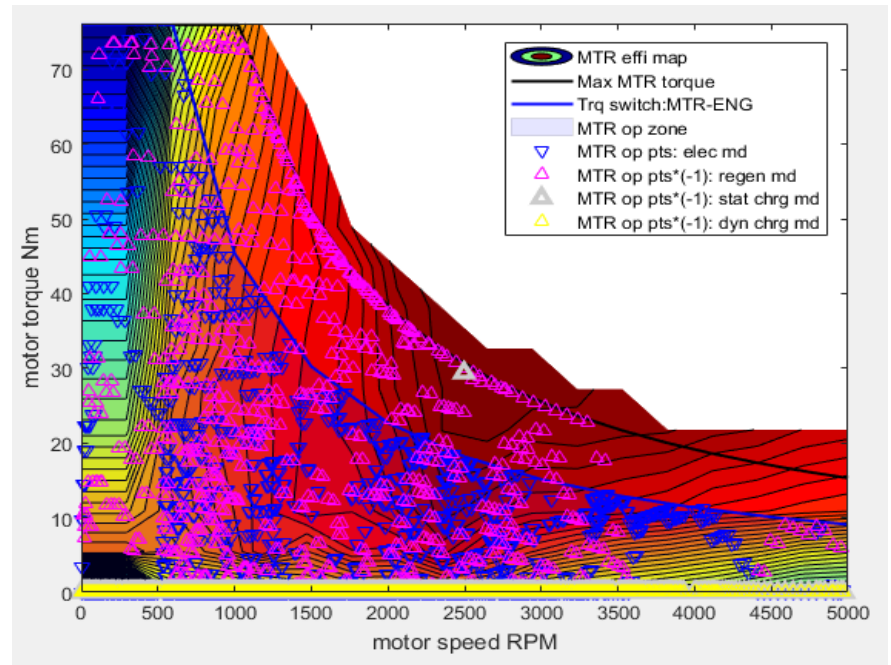

Fig. 37. Motor operating points for P4 on WLTC

In Fig. 37 motor operation for traction (blue) and regeneration (pink) modes is widespread with no control over its exact placement due to lack gear selections. This certainly relates to some loss in overall electric drive efficiency.

As the electric - engine switch traction power level for P4 $(4750 \mathrm{~W})$ is low, the powertrain is mostly able to maintain its SOC by regenerative braking (Fig. 38, Fig. 39) and just using the static charging mode for a small duration due to lower battery usage although over several consecutive WLTC driving cycles dynamic charging is also activated to charge up the battery (not shown here). 


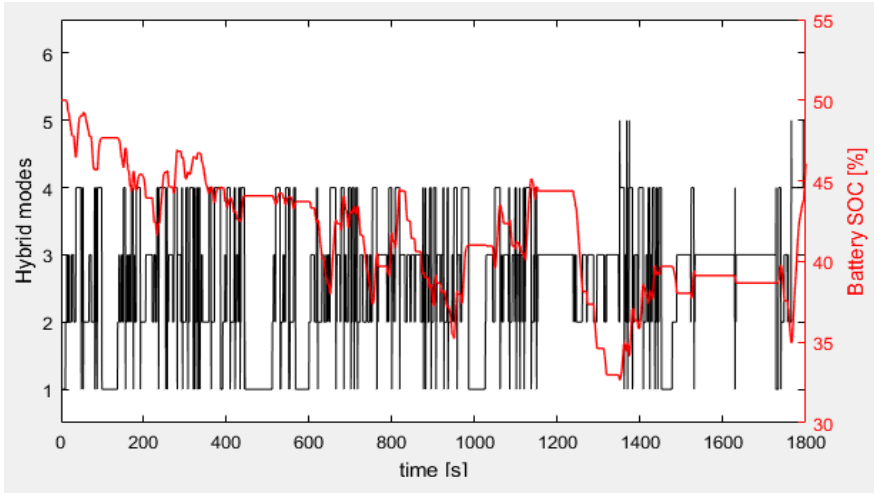

Fig. 38. Battery SOC for P4 on WLTC

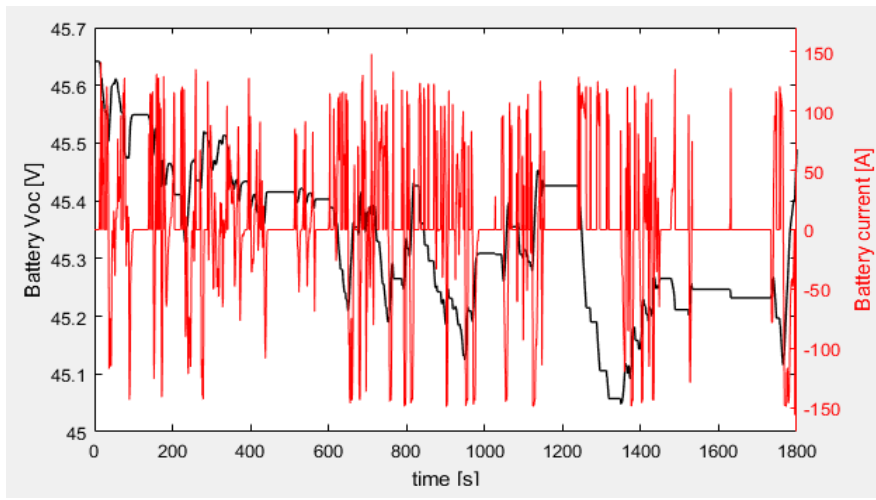

Fig. 39. Battery Voc and I bat for P4 on WLTC

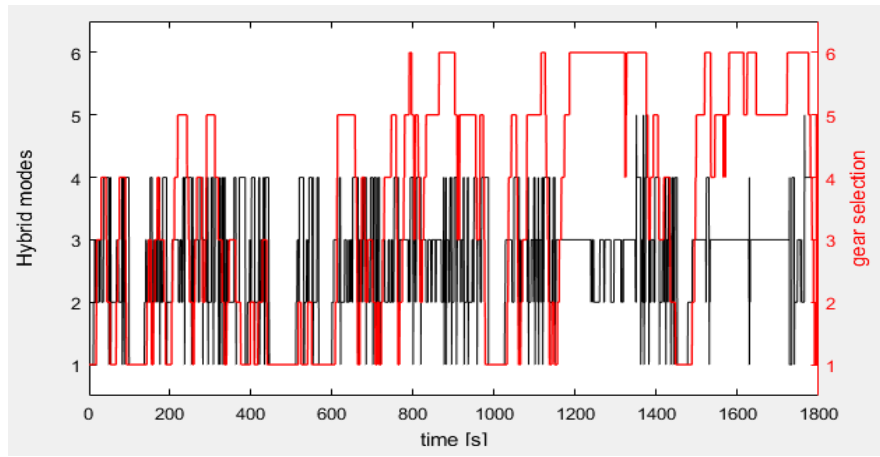

Fig. 40. Gear selection for P4 on WLTC

As the gearbox is now not used for controlling electric motor operation the gear change only follows needs of the engine operation as can be seen by comparing Fig. 40 with Fig. 28 .

\section{4) P4 hybrid + CVT}

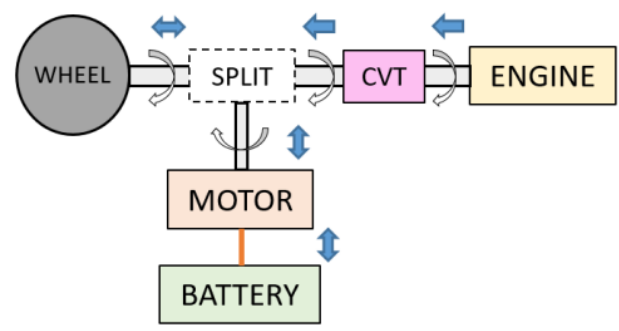

In this P4 setup, the conventional transmission with fixed shift strategy is replaced by a CVT with optimal power line based control. The electric motor is given the same single gear reduction (4.8:1) to cover the most possible drastic operating points that come inside the electric power range as in the standard $\mathrm{P} 4$ case.

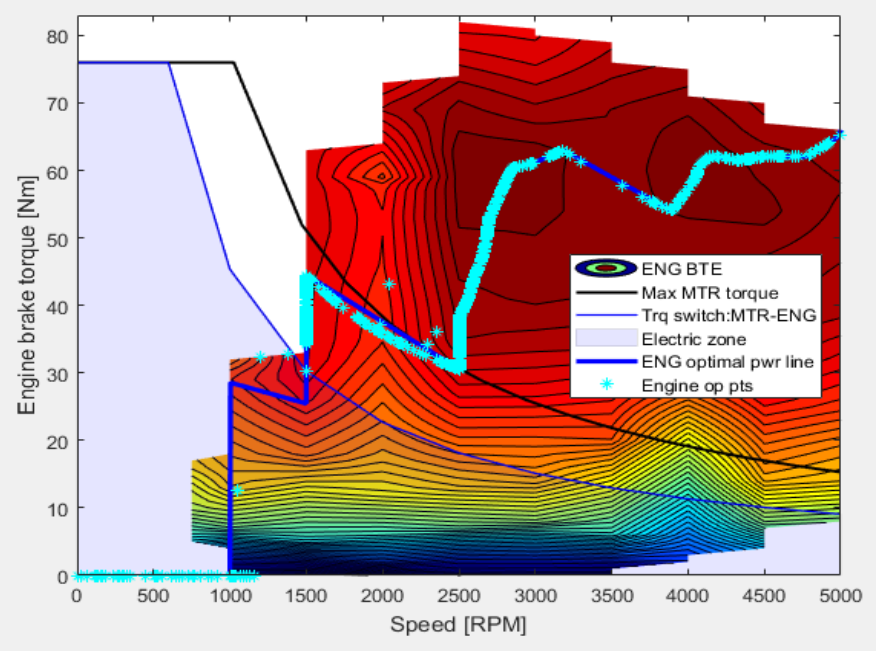

Fig. 42. Engine operating points for P4 + CVT on WLTC

Fig. 42 shows that the CVT gearbox makes the combustion engine properly follow the optimal power line although some operating points fall below in the calibrated electric switch output region $P_{\text {switch }}=4750 \mathrm{~W}$ (blue) as the motor is not able to function here due to crossing of its torque or speed limits.

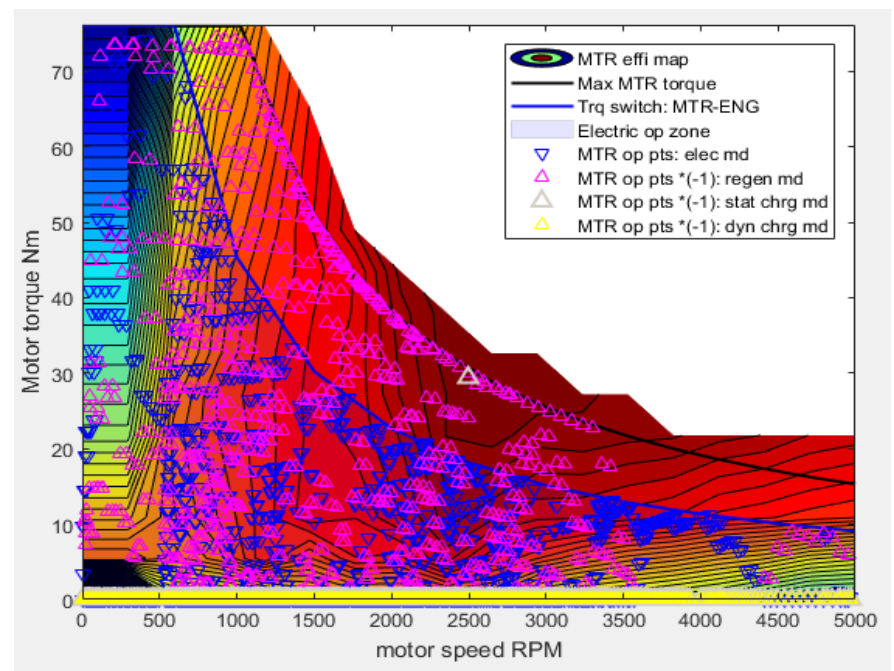

Fig. 43. Motor operating points for P4 + CVT on WLTC

The electric system operation for P4 and P4 + CVT architectures is the same as the transmission change does not to affect the electric drive functioning to a great extent and the only change can occur in charging modes where the transmission efficiency variation between standard and CVT would result in charging efficiency difference. These factors result in almost the same operating points placement and other properties for both cases Fig. 43, and Fig. 37.

Fig. 41. P4 hybrid powertrain architecture with CVT 


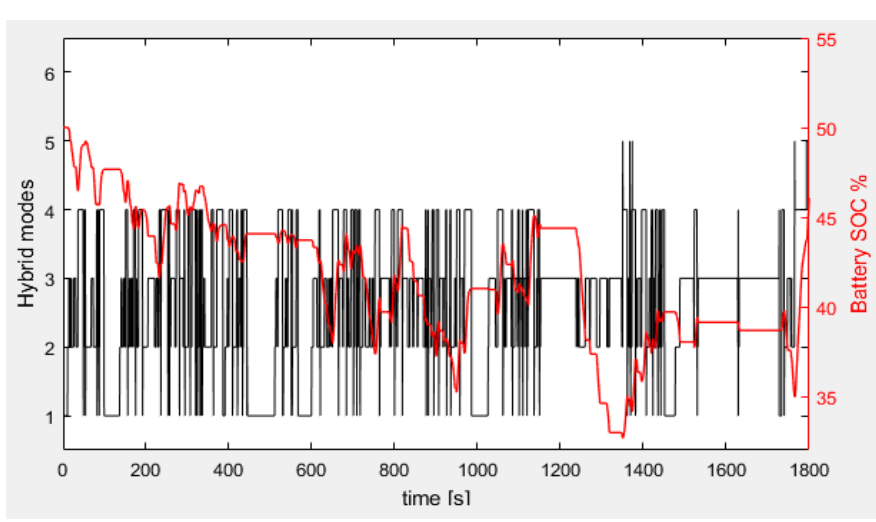

Fig. 44. Battery SOC for P4 + CVT on WLTC

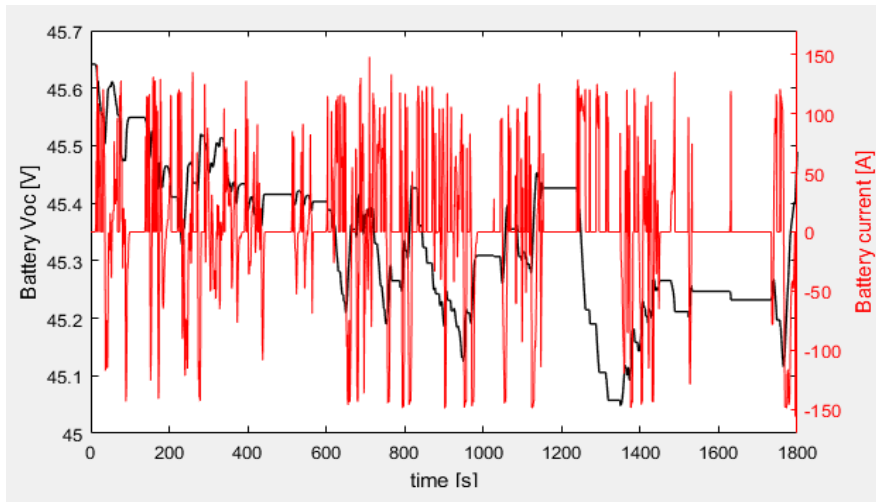

Fig. 45. Battery Voc and I bat for P4 + CVT on WLTC

Variation in SOC, $V_{o c}$ and $I_{b a t}$ along the driving cycle is very similar to standard P4 setup as the hybrid operation with the change in transmission does not affect the electric drive functioning (compare with Fig. 38 and Fig. 39).

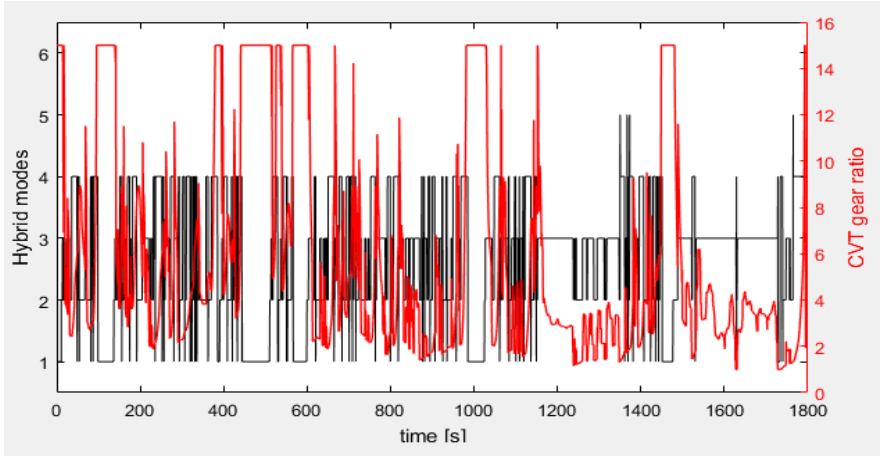

Fig. 46. CVT gear ratios for P4 + CVT on WLTC

As the CVT gearbox is not used for controlling the electric motor operation, the gear ratios only follow the needs of efficient engine operation which can be realized further when comparing Fig. 46 with Fig. 34.

\section{G. Fuel efficiency analysis for mild hybrid}

Fig. 47 shows the fuel efficiency and $\mathrm{CO} 2$ emission simulation results after a coarse calibration of the single tuning parameter $P_{\text {switch }}$ for the four selected 48v hybrid architectures. For all cases, at a certain $P_{\text {switch }}$ value the lowest overall consumption and highest combined powertrain efficiency is found where the best compromise in avoiding losses in the combustion engine, electric drive, battery, and transmission is found over the whole driving cycle.

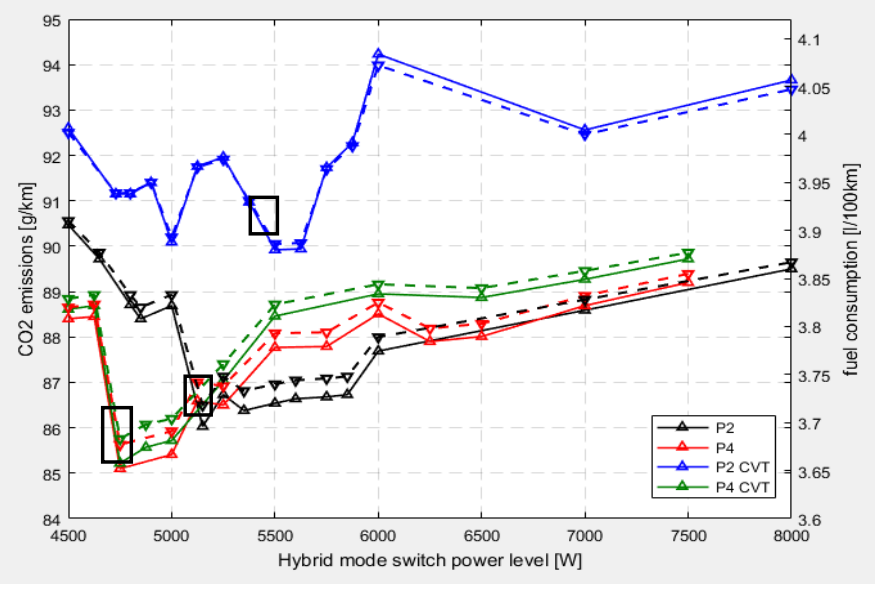

Fig. 47. P_switch - fuel consumption (dashed) and CO2 emissions for $48 \mathrm{v}$ hybrid architectures

It can be seen that the best performance is found from the standard P4 architecture followed closely by P4 + CVT result at exactly the same power switch calibration $\left(P_{\text {switch }}=4750\right.$ $\mathrm{W})$. Then comes standard P2 case and in the end with some gap P2 + CVT at increasing $P_{\text {switch }}$ levels.

Such spread of optimal $P_{\text {switch }}$ levels is related to the less efficient charging for $\mathrm{P} 4$ cases due to transmission losses and also restricted operation of the electric motor due to crossing of its torque and speed limits for both traction and regenerative braking modes. For P2 both static and dynamic charging is more efficient as there are no transmission losses, and the motor operation for traction and recuperation is more effective and widespread with the possible usage of the gearbox for the electric motor. This facilitates more electric only operation. For $\mathrm{P} 2+\mathrm{CVT}$ case it is seen that the electric operation is even more promoted as the CVT with higher losses is now being used for the electric motor operation which at lower traction power is still more efficient than using the combustion engine + CVT combination.

TABLE 4 COMPARISON OF FUEL CONSUMPTION: MILD HYBRID AND CVT ARCHITECTURES

\begin{tabular}{|l|l|l|l|l|}
\hline Architecture & $\begin{array}{c}\text { Power } \\
\text { switch level } \\
{[\text { W] }}\end{array}$ & $\begin{array}{c}\text { fuel } \\
\text { economy } \\
{[\text { [l/100km] }}\end{array}$ & $\begin{array}{c}\text { Percent \% } \\
\text { improvement } \\
\text { on standard }\end{array}$ & $\begin{array}{c}\text { CO2 } \\
{[\mathbf{g} / \mathbf{K m}]}\end{array}$ \\
\hline P2 & 5350 & 3.733 & 19.07 & 86.38 \\
\hline P2 + CVT & 5050 & 3.824 & 17.10 & 88.5 \\
\hline P4 & 4750 & 3.677 & 20.29 & 85.1 \\
\hline P4 + CVT & 4750 & 3.683 & 20.16 & 85.22 \\
\hline
\end{tabular}

When comparing results for efficiency in our specific vehicle application, scenario $\mathrm{P} 4$ performs the best followed closely by P4 + CVT as after implementation of mild hybrid system the CVT transmission no longer offers better overall savings over the standard transmission. This can be related to 
three factors: for lower engine torque or speed zones the CVT engine combination is not being used where it was effective, lower CVT transmission efficiency even if it is able to place the engine operation in higher efficiency zones, and inefficient charging as compared to the standard case.

The effect of lower CVT efficiency can also be seen when comparing the two P2 setups where the difference in fuel consumption for CVT and non CVT case is much greater as compared to the P4 cases as now its presence affects both combustion engine and electric motor operation negatively.

When comparing P2 with P4 setups for efficiency it seems that the performance lacks simply because the $\mathrm{P} 4$ setups are better suited to this combination of vehicle, powertrain, and driving cycle characteristics. For this specific case, the effect of losses in power transmission tends to be greater than the effect of the hindrance of motor functioning due to its limits that is the drawbacks and advantages combination discussed earlier for P4 setups is better suited to our application as compared to the P2 setups. The overall result may completely vary if any simple parameter such as vehicle weight is changed.

\section{IV.CONCLUSION}

1. Innovative control strategies such as start-stop, coasting, and optimized gear shift have a significant potential in making the current vehicles emission norms complaint and in pushing the transition towards clean and efficient mobility.

2. The efficient application of CVT under the ideal case with ideal control is a question of finding the best compromise between how much is gained in engine efficiency against how much is lost in power transmission. Depending on the application, the CVT may or may not be a good alternative to conventional transmission.

3. 48v mild hybridization, and CVT transmission combinations show even better efficiency results, a proof of their effectiveness being the discussed application where a powertrain from 2001 could be made current $\mathrm{CO} 2$ emission limits compliant.

4. Hybrid powertrain development is about finding the best compromise amongst efficient usage of its different components towards overall high powertrain efficiency.

5. The study has given an idea about the interlinking of architecture selection, sizing, control, and calibration steps in hybrid system development and how they need to be overlapped or sometimes carried together for attaining the best results. This shows the even greater importance of simulation based engineering which is very cost-effective in trying and testing the changing of architectures, controls, and application of new technologies.

\section{REFERENCES}

[1] L. Guzzella, \& A. Sciarretta, "Vehicle Propulsion Systems: Introduction to Modeling and Optimization," Springer, 2013.

[2] J. Larminie, \& J. Lowry, "Electric Vehicle Technology Explained, 2nd Edition," WILEY, 2012.

[3] S. Lauer, F. Graf, M. Springer, \& S. Wechler, Continental Automotive $\mathrm{GmbH}$, "48 Volt hybrid with e-drive features - excellent fuel efficiency and drivability," Electric \& Electronic Systems in Hybrid and Electrical Vehicles and Electrical Energy Management, Bamberg, 2017.

[4] B. Fu, Y. Zhou, C. Cao, Q. Li, \& F. Zhang, "Research on power loss of continuously variable transmission based on driving cycles," Series: Earth and Environmental Science ESMA, 2017.
[5] S. Lee, B. Lee, J. McDonald, L. J. Sanchez, \& E. Nam, US Environmental Protection Agency, "Modeling and Validation of PowerSplit and P2 Parallel Hybrid Electric Vehicles," SAE International, 2013.

[6] HITACHI Vehicle Energy, Ltd., "Development of 48V lithium-ion battery pack with improved output density and energy density developed for mild hybrid vehicles," Tokyo, 2017.

[7] T. Bradley, \& K. Stanton, "Hybrid electric vehicle architectures," 2018.

[8] Available:www.academia.edu/7437278/Hybrid_Electric_Vehicle_Arch itectures

[9] L. W. Soong, G. Pellegrino, A. Mahmoudi \&. E. Armando, "Efficiency maps of electrical machines," Energy Conversion Congress and Exposition (ECCE), Montreal, 2015.

[10] B. Mackay, "Benefits of a 48v P2 mild hybrid," Continental AG, 2016.

[11] T. Markel, A. Brooker, \& T. Hendricks, "ADVISOR: a systems analysis tool for advanced vehicle modelling," Journal of Power Sources, 2002.

[12] Continental Automotive, "Worldwide emission standards and related regulations," 2019.

[13] Available:https://www.auto-data.net/fr/smart-fortwo-coupe-0.6i-45hp14875

[14] Available:https://www.driverside.com/specs/smart-fortwo-2013-3098054223-0

[15] Available:https://www.evilution.co.uk/info/gear_ratios.htm

APPENDIX

TABLE 5 PHYSICAL PARAMETERS

\begin{tabular}{|c|c|}
\hline Vehicle & Smart Fortwo - 2001 [13] \\
\hline Vehicle mass (one passenger) $m[\mathrm{Kg}]$ & 880 \\
\hline $\begin{array}{l}\text { Vehicle mass (one passenger) } \\
+48 \mathrm{v} \text { hybrid system }[\mathrm{Kg}]\end{array}$ & 920 \\
\hline Aerodynamic drag coefficient & 0.35 \\
\hline Frontal area $A\left[\mathrm{~m}^{2}\right]$ & 1.95 \\
\hline Vehicle wheel radius $r_{w}[\mathrm{~m}]$ & 0.2884 \\
\hline Rotational inertia of each wheel $\left[\mathrm{Kgm}^{2}\right]$ & 0.28 \\
\hline Engine & $\begin{array}{l}\text { 599cc } 34[\mathrm{KW}](45 \mathrm{hp}) \\
\text { turbo 3-cylinder engine } \\
\text { (Fig. 2) }\end{array}$ \\
\hline Engine rotational inertia $J_{e n g}\left[\mathrm{Kgm}^{2}\right]$ & 0.075 \\
\hline Transmission & $\begin{array}{l}6 \text { speed with two final } \\
\text { drives }\end{array}$ \\
\hline $\begin{array}{l}\text { Original vehicle gear ratios } \\
\text { (final ratios) }\end{array}$ & $\begin{array}{l}\text { Two different final drives } \\
\text { and three gears giving } 6 \\
\text { speeds [15] }\end{array}$ \\
\hline Gear ratio 1 & 14.203 \\
\hline Gear ratio 2 & 10.310 \\
\hline Gear ratio 3 & 7.407 \\
\hline Gear ratio 4 & 5.625 \\
\hline Gear ratio 5 & 4.083 \\
\hline Gear ratio 6 & 2.933 \\
\hline $\begin{array}{l}\text { Transmission rotational inertia } J_{\text {trns }} \\
{\left[\mathrm{Kgm}^{2}\right]}\end{array}$ & 0.2 \\
\hline Hybrid system & $48 \mathrm{v}$ mild hybrid \\
\hline Battery architecture & 12 cells in series \\
\hline Battery weight $[\mathrm{Kg}]$ & 8 \\
\hline Nominal voltage [V] & 48 \\
\hline Charge capacity [Ah] & 8 \\
\hline Max electric motor power [W] & 8000 \\
\hline Motor weight $[\mathrm{Kg}]$ & 10 \\
\hline $\begin{array}{l}\text { Overall weight including power electronics } \\
\text { and mountings }[\mathrm{Kg}]\end{array}$ & 40 \\
\hline \multicolumn{2}{|l|}{ Ambient properties } \\
\hline Air temperature $[\mathrm{K}]$ & 300 \\
\hline Specific gas constant $\mathrm{R}$ & 287 \\
\hline Ambient air pressure $[\mathrm{Pa}]$ & 101325 \\
\hline Air density $\rho\left[\mathrm{Kg} / \mathrm{m}^{3}\right]$ & 1.202 \\
\hline Acceleration due to gravity $\left[\mathrm{m} / \mathrm{s}^{2}\right]$ & 9.81 \\
\hline Fuel properties & Gasoline \\
\hline Gasoline fuel energy density LHV [J/Kg] & 42500000 \\
\hline Fuel $[\mathrm{Kg} / \mathrm{L}]$ & 0.7489 \\
\hline
\end{tabular}

